Aline Lázara Resende

\title{
Doença óssea em pacientes com nefrite lúpica: aspectos inflamatórios
}

Tese apresentada à Faculdade de Medicina da Universidade de São Paulo para obtenção do Título de Doutor em Ciências

Programa de: Nefrologia

Orientadora: Prof. Dra. Viktoria Woronik

\section{São Paulo}


Dados Internacionais de Catalogação na Publicação (CIP)

Preparada pela Biblioteca da

Faculdade de Medicina da Universidade de São Paulo

Creprodução autorizada pelo autor

Resende, Aline Lázara

Doença óssea em pacientes com nefrite lúpica : aspectos inflamatórios / Aline Lázara Resende. -- São Paulo, 2014.

Tese(doutorado)--Faculdade de Medicina da Universidade de São Paulo.

Programa de Nefrologia.

Orientadora: Viktoria Woronik.

Descritores: 1.Mulheres 2.Pré-menopausa 3.Lúpus eritematoso sistêmico 4.Nefrite lúpica 5.Vitamina D 6.Inflamação 7.Doenças ósseas 8.Histologia

USP/FM/DBD-033/14 


\section{Dedicatória}


Aos meus pais, Jairo e Maria José, por me incentivarem sempre e despertarem em mim o prazer pelo conhecimento.

Ao Ivan, meu bem, por ampliar meu mundo e me fazer melhor a cada dia. 
Agradecimentos 
A Dra Viktoria Woronik por ter acreditado em mim, quando eu era apenas uma goiana recém-chegada a São Paulo com uma idéia abstrata sobre a pós-graduação. Agradeço pelo apoio, pela companhia, pela paciência, e pelos ensinamentos sobre nefrologia e sobre a vida.

Aos colaboradores e amigos do LIM 16 (Dra Luciene Machado dos Reis, Dra Vanda Jorgetti, Wagner Vasques Dominguez, Dra Fabiana Giorgeti Graciolli, Dra Rosa Maria Affonso Moysés, Dra Cristiane Bitencourt Dias, Rita de Cássia Tedeschi Martin, Rosimeire Aparecida Bizerra da Costa, Dra Melani Ribeiro Custódio), sem os quais esse trabalho jamais seria possível. Obrigada por terem me ensinado sobre as motivações, sonhos e realidade da vida de um pesquisador. Aos colegas de pós-graduação e laboratório (Veronica, Tatiana e Raquel), agradeço pelos almoços e pelas conversas, por dividirem comigo alegrias e dificuldades.

Agradeço aos funcionários do HC (Hospital Dia, Ambulatório, Enfermaria e Laboratório da Nefrologia) pelo profissionalismo, disponibilidade e atenção; e as pacientes, por permitiram que eu fizesse parte de suas vidas mesmo em um momento tão delicado.

A Dra Silvia Titan, que, de mestre, passou a amiga e colega de trabalho. Obrigada por me incentivar a pensar, pelo bom-senso, pelo exemplo, pelas oportunidades.

A minha querida amiga/irmã Rachel Portela, com quem dividi não só um apartamento, mas também muitas angústias, dúvidas, vitórias e aprendizado.

Por fim, agradeço aos colegas de trabalho e amigos de Barueri e do Hospital Sírio Libanês, por viabilizarem minha vida econômica, engrandecerem minha vida profissional e preencherem minha vida pessoal em São Paulo. 
Essa tese está de acordo com:

Referências: adaptado de International Committee of Medical Journal Editors (Vancouver)

Universidade de São Paulo. Faculdade de Medicina. Serviço de Biblioteca e Documentação; Guia de apresentação de dissertações, teses e monografias. Serviço de Biblioteca e Documentação; 2011.

Abreviaturas dos títulos dos periódicos de acordo com List of Journals Indexed in Index Medicus. 
Sumário 
LISTA DE ABREVIATURAS E SIGLAS

LISTA DE FIGURAS

LISTA DE TABELAS

RESUMO

SUMMARY

1.INTRODUÇÃO.

1.1. INFLAMAÇÃO E FISIOPATOLOGIA DO LES .................................... 3

1.2. COMPROMETIMENTO ÓSSEO NO LES …......................................... 5

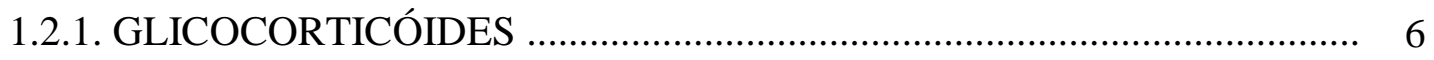

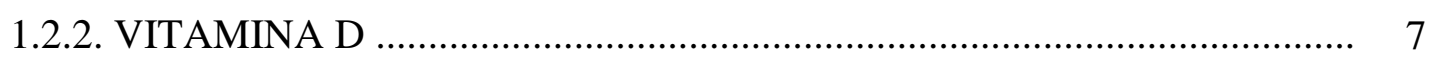

1.2.2.1. O PAPEL DA PROTEINÚRIA ................................................ 8

1.2.2.2. DISFUNÇÃO RENAL ....................................................... 9

1.2.3. FATORES INFLAMATÓRIOS _............................................................. 11

1.3. OSTEOIMUNOLOGIA: ATIVIDADE INFLAMATÓRIA E

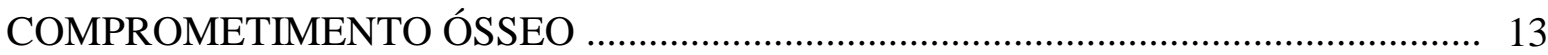

1.3.1. OSTEOPROTEGERINA E SISTEMA RANK-RANKL ......................... 14

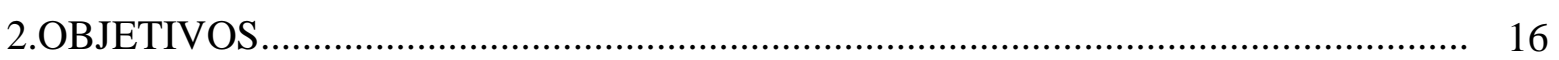

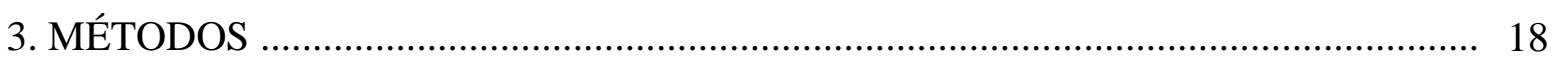

3.1. POPULAÇÃO ESTUDADA _................................................................... 19

3.2. ANÁLISE CLÍNICO-LABORATORIAL .................................................. 20

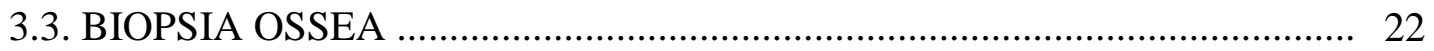

3.3.1. CULTURA DE CÉLULAS ÓSSEAS ........................................ 23

3.3.1.1. PROLIFERAÇÃO CELULAR ................................................. 24

3.3.1.2. CITOMETRIA DE FLUXO .................................................. 25

3.3.2. HISTOMORFOMETRIA E IMUNOHISTOQUÍMICA ................ 27

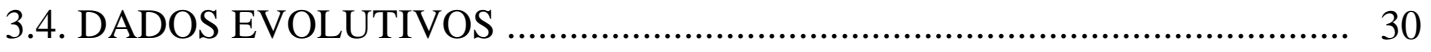

3.5. ANÁLISE ESTATÍSTICA …................................................................. 30

3.6. RECURSOS FINANCEIROS ................................................................ 31

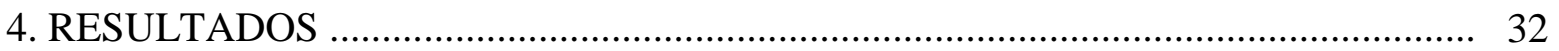

4.1. CARACTERÍSTICAS CLÍNICO-LABORATORIAIS .............................. 33

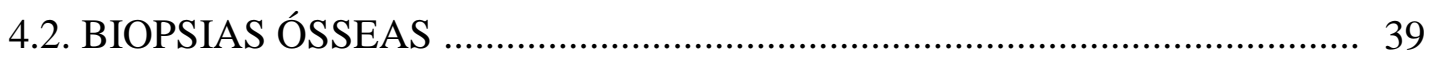

4.2.1. CULTURA DE CÉLULAS ÓSSEAS ........................................ 39 
4.2.2. HISTOMORFOMETRIA _......................................................... 42

4.2.3. IMUNOHISTOQUÍMICA ................................................... 46

4.3. DADOS EVOLUTIVOS .............................................................. 47

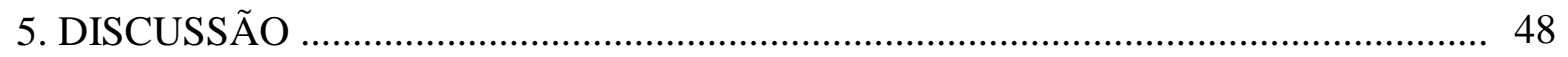

5.1. CONSIDERAÇÕES FINAIS _.......................................................... 53

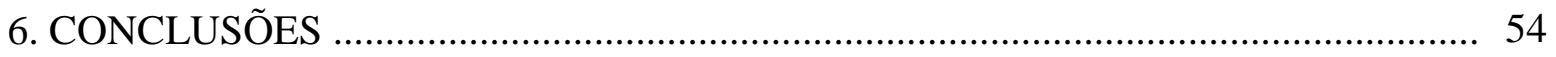

7. REFERÊNCIAS BIBLIOGRÁFICAS ….......................................................... 56 


\section{Lista de abreviaturas e siglas}




\section{LISTA DE ABREVIATURAS E SIGLAS}

\begin{tabular}{|c|c|}
\hline $\mathrm{BFR} / \mathrm{BS}$ & Taxa de formação óssea \\
\hline $\mathrm{BV} / \mathrm{TV}$ & Volume trabecular \\
\hline DMO & Densidade Mineral Óssea \\
\hline DMO-DRC & Distúrbio mineral e ósseo da doença renal crônica \\
\hline DRC & Doença renal crônica \\
\hline ES/BS & Superfície de reabsorção \\
\hline FGF-23 & Fibroblast growth factor 23 \\
\hline IL & Interleucina \\
\hline IMC & Índice de massa corpórea \\
\hline LES & Lupus eritematoso sistêmico \\
\hline MAR & Taxa de aposição mineral \\
\hline MCP-1 & Monocyte Chemoattractant Protein-1 \\
\hline MLT & Tempo de mineralização \\
\hline MS/BS & Superfície mineralizante \\
\hline NL & Nefrite lúpica \\
\hline O.Th & Espessura osteóide \\
\hline Ob.S/BS & Superfície osteoblástica \\
\hline Oc.S/BS & Superfície osteoclástica \\
\hline OPG & Osteoprotegerina \\
\hline OS/BS & Superfície osteóide \\
\hline $\mathrm{OV} / \mathrm{BV}$ & Volume osteóide \\
\hline PTH & Hormônio Paratiroidiano \\
\hline RANK & Receptor ativador do fator nuclear- $\kappa \mathrm{B}$ \\
\hline RANKL & Receptor ativador do fator nuclear- $\kappa \mathrm{B}$ ligante \\
\hline SLEDAI & Systemic Lupus Erythematosus Disease Activity Index \\
\hline Tb.N & Número de trabéculas \\
\hline Tb.Sp & Separação trabecular \\
\hline Tb.Th & Espessura trabecular \\
\hline TFG & Taxa de Filtração Glomerular \\
\hline TNF & Fator de Necrose Tumoral \\
\hline $1,25(\mathrm{OH}) \mathrm{D}_{3}$ & 1,25-dihidroxivitamina $\mathrm{D}_{3}$ \\
\hline $25(\mathrm{OH}) \mathrm{D}$ & 25-hidroxivitamina $\mathrm{D}_{3}$ \\
\hline
\end{tabular}


Lista de figuras 


\section{LISTA DE FIGURAS}

Figura 1: Osteoprotegerina e sistema RANK-RANKL: relação entre mediadores inflamatórios, sistema imune e metabolismo ósseo ........................................................ 15

Figura 2: Correlação entre os níveis de 25(OH)D e mediadores inflamatórios ................. 36

Figura 3: Expressão de MCP-1 pela citometria de fluxo em células ósseas de pacientes lúpicas (A) e controles (B) 41

Figura 4: Aspecto histológico do tecido ósseo de paciente lúpica (A) e de individuo controle (B)

Figura 5: Aspecto histológico do tecido ósseo de pacientes lúpicas (A,C) e de individuo saudável (B)

Figura 6: Expressão de osteoprotegerina em biópsias ósseas de pacientes com nefrite lúpica (A) e de indivíduos controles (B)

Figura 7: Expressão de RANKL em biópsias ósseas de paciente com nefrite lúpica (A) e de individuos controles (B) 
Lista de tabelas 


\section{LISTA DE TABELAS}

Tabela 1: Características clínico-laboratoriais das pacientes lúpicas

Tabela 2: Características clínicas e laboratoriais das portadoras de nefrite lúpica e dos controles

Tabela 3: Modelo de regressão linear utilizando log MCP-1 urinário como variável dependente

Tabela 4: Características clínico-laboratoriais das pacientes lúpicas e dos controles portadores de glomerulopatias primárias

Tabela 5: Características clínico-laboratoriais e resultados dos experimentos de cultura (proliferação celular e pela citometria de fluxo) nas pacientes lúpicas e controles 40

Tabela 6: Parâmetros histomorfométricos das pacientes portadoras de nefrite lúpica e controles

Tabela 7: Parâmetros histomorfométricos das pacientes lúpicas e controles portadores de glomerulopatias primárias

Tabela 8: Expressão de osteoprotegerina e RANKL em biópsias ósseas de pacientes portadoras de nefrite lúpica e controles 
Resumo 


\section{Resende AL. Doença óssea em pacientes com nefrite lúpica: aspectos inflamatórios [tese]. São Paulo: Faculdade de Medicina, Universidade de São Paulo; 2014.}

INTRODUÇÃO: O comprometimento ósseo em pacientes portadoras de nefrite lúpica é comum e multifatorial. O objetivo deste trabalho foi estudar a contribuição do componente inflamatório para o comprometimento ósseo destas pacientes. MÉTODOS: Foram estudadas 15 pacientes do sexo feminino (no menacme) com diagnóstico recente ( $\leq 2$ meses) de Lupus Eritematoso Sistêmico e Nefrite Lúpica (NL). Foram excluídos pacientes com história/evidência de doença renal ou óssea prévia. A avaliação laboratorial incluiu a dosagem de 25-hidroxivitamina $\mathrm{D}_{3}([25(\mathrm{OH}) \mathrm{D}]$ e de citocinas inflamatórias associadas a fisiopatologia do lupus [Interleucina-6, Fator de necrose tumoral $\alpha$ e Monocyte Chemoattractant Protein-1 (MCP-1)]. Além disso, as pacientes foram submetidas a biópsia óssea, com análise histomorfométrica, imunohistoquímica e cultura celular (estudo da proliferação e citometria de fluxo). RESULTADOS: As pacientes lúpicas apresentavam em média 29,5 \$10 anos, com uma proteinúria de

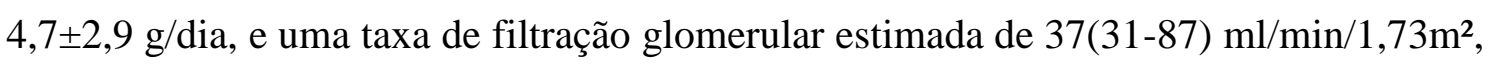
e estavam em uso de glicocorticóide por $34 \pm 12$ dias. Todas as pacientes apresentavam níveis insuficientes de vitamina $\mathrm{D}(9,9 \pm 4,4 \mathrm{ng} / \mathrm{ml}$, variando de 4 a $20 \mathrm{ng} / \mathrm{ml})$. Os níveis de $25(\mathrm{OH}) \mathrm{D}$ se correlacionaram negativamente com os de todas as citocinas inflamatórias estudadas. Os níveis de MCP-1 urinário se correlacionaram negativamente com os de $25(\mathrm{OH}) \mathrm{D}(\mathrm{r}=-0,53, \mathrm{p}=0,003)$ e positivamente com os de deoxipiridinolina $(\mathrm{r}=0,53, \mathrm{p}=0,004)$. Não observamos diferença significativa entre pacientes e controles na proliferação de osteoblastos medida pela incorporação pela timidina $(82,22 \pm 8,43 v s$ $56,06 \pm 23,73$ contagem por minuto, $\mathrm{p}=0,21)$. Os osteoblastos provenientes dos fragmentos ósseos das pacientes lúpicas apresentaram uma maior expressão de MCP-1, medida pela intensidade média de fluorescência $(32,0 \pm 9,1$ vs $22,9 \pm 5,3, \mathrm{p}=0,01)$. Quando comparadas a controles, as pacientes portadoras de nefrite lúpica apresentaram valores significativamente inferiores de dois parâmetros de formação óssea (volume e espessura osteoide). Além disso, detectamos também uma redução em dois parâmetros de mineralização óssea (superfície mineralizante e taxa de formação óssea). Por fim, as pacientes lúpicas apresentaram um aumento significativo da reabsorção óssea e da superfície osteoclástica. Com relação a imunohistoquímica, as pacientes lúpicas 
apresentaram uma menor expressão de osteoprotegerina $(0,61 \pm 0,82$ vs $1,08 \pm 0,50$, $\mathrm{p}=0,003$ ) e uma maior expressão do receptor ativador do fator nuclear- $\kappa \mathrm{B}$ ligante (RANKL) $(1,76 \pm 0,92$ vs $0,41 \pm 0,28, \mathrm{p}<0,001)$ quando comparadas aos controles. CONCLUSÕES: Pacientes com diagnóstico recente de nefrite lúpica, submetidas a um reduzido tempo de exposição e carga cumulativa de corticóide, apresentam um significativo comprometimento ósseo, caracterizado por uma redução da formação e mineralização óssea, associada a um aumento da reabsorção óssea. Os níveis de MCP-1 urinário se correlacionaram negativamente com os de 25-hidroxivitamina $D_{3}$ e positivamente com os de deoxipiridinolina, sugerindo que fatores inflamatórios possam contribuir para a insuficiência de vitamina $\mathrm{D}$ e a reabsorção óssea. A expressão óssea aumentada de RANKL e reduzida de OPG, assim como o aumento da expressão de MCP-1 pelas células ósseas das pacientes lúpicas, reiteram a hipótese de que a inflamação per se possa influenciar a reabsorção óssea observada nestas pacientes.

Descritores: Mulheres; Pré-menopausa; Lúpus eritematoso sistêmico; Nefrite lúpica; Vitamina D; Inflamação; Doenças Ósseas; Histologia. 


\section{Summary}




\section{Resende AL. Bone disease in lupus nephritis patients: inflammatory aspects}

[thesis]. São Paulo: Faculdade de Medicina, Universidade de São Paulo; 2014.

INTRODUCTION: Bone disease in lupus nephritis patients is common and multifactorial. The aim of this study was evaluate the contribution of inflammatory factors to the bone disorder observed in these patients. METHODS: We studied 15 female pre-menopausal patients with $\leq 2$ months of diagnosed Systemic Erythematosus Lupus and Lupus Nephritis (LN). Subjects with prior kidney or bone disease were excluded. We measured the levels of 25-hydroxyvitamin $\mathrm{D}_{3}[25(\mathrm{OH}) \mathrm{D}]$ and cytokines involved in LN physiopathology [Interleucin-6, Tumor Necrosis Factor $\alpha$, and Monocyte Chemoattractant Protein-1 (MCP-1)]. Patients were submitted to bone biopsy, followed by osteoblast culture (cell proliferation and flow cytometry), histomorphometric and immunohistochemistry analysis. RESULTS: LN patients presented a mean age of $29.5 \pm 10$ years, a proteinuria of $4.7 \pm 2.9 \mathrm{~g} /$ day and an estimated glomerular filtration rate of $37(31-87) \mathrm{ml} / \mathrm{min} / 1,73 \mathrm{~m}^{2}$. They were on glucocorticoid therapy for $34 \pm 12$ days. All patients presented vitamin D insufficiency $(9.9 \pm 4.4 \mathrm{ng} / \mathrm{ml}$, range 4-20). Vitamin D levels were negatively correlated with all inflammatory cytokines. Urinary MCP-1 correlated negatively with 25-hydroxyvitamin $\mathrm{D}_{3}(\mathrm{r}=-0.53$, $\mathrm{p}=0.003)$ and positively with serum deoxypyridinoline $(\mathrm{r}=0.53, \mathrm{p}=0.004)$. There were no differences between NL patients and controls in osteoblast proliferation measured by incorporation of thymidine $(82.22 \pm 48.43$ vs $56.07 \pm 23.73$ counts per minute, respectively, $\mathrm{p}=0.21$ ). Osteoblasts isolated from $\mathrm{LN}$ patients presented a significantly higher expression of MCP-1, as measured by mean fluorescence intensities (32.0 $\pm 9.1 \mathrm{vs}$ $22.9 \pm 5.3, \mathrm{p}=0.01)$. $\mathrm{LN}$ patients presented a significantly reduction in two formation parameters (osteoid volume and osteoid thickness). They also presented a decrease in mineralization surface and bone formation rate, associated with an increased eroded surface and osteoclast surface. Patient's bone specimens demonstrated a reduced immunostaining for osteoprotegerin $(0.61 \pm 0.82$ vs $1.08 \pm 0.50 \%, \mathrm{p}=0.003)$, and an

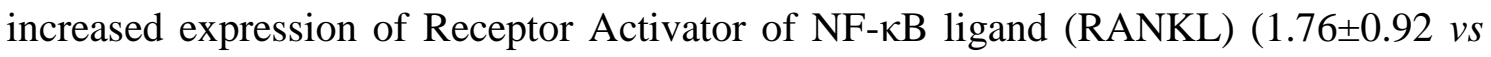
$0.41 \pm 0.28 \%, \mathrm{p}<0.001)$ when compared to controls. CONCLUSION: Newly diagnosed lupus nephritis patients, submitted to a limited time of exposure and to a low cumulative dose of glucocorticoids, presented a significant disturbance in bone metabolism, 
characterized by an impaired bone formation and mineralization, associated with an increase in resorption parameters. The levels of urinary MCP-1 were negatively correlated to 25-hydroxyvitamin $\mathrm{D}_{3}$ and positively correlated to serum deoxypyridinoline, suggesting that inflammation may contribute to vitamin $D$ insufficiency and bone resorption. Bone tissue overexpression of RANKL and underexpression of osteoprotegerin, as well as increased expression of MCP-1 by cultured bone explants cells reinforces inflammatory background contributing to bone resorption in $\mathrm{LN}$ bone disease.

Descriptors: Women; Premenopausal; Lupus erythematosus, systemic; Lupus nephritis; Vitamin D; Inflammation; Bone Diseases; Histology. 
Introdução 


\section{Introdução}

O Lupus Eritematoso Sistêmico (LES) é uma doença auto-imune que cursa com manifestações clínico-laboratoriais, evolução e prognóstico variáveis (1). O comprometimento renal (Nefrite Lúpica) é uma manifestação grave, podendo ocorrer precocemente em até $30 \%$ dos casos (2).

Nas últimas décadas, têm-se observado um aumento significativo na sobrevida geral e renal dos pacientes com nefrite lúpica (NL), atribuído essencialmente a dois fatores: o diagnóstico precoce e o tratamento imunossupressor agressivo (3-6). Em função desta tendência, têm aumentado também a preocupação da comunidade científica com a prevenção e manejo das comorbidades relacionadas ao LES e ao seu tratamento.

O comprometimento ósseo em pacientes portadores de LES é uma complicação muito comum, com taxas de osteopenia e osteoporose variando de $25-74 \%$ e 1,4-68\%, respectivamente $(7,8)$. No entanto, sua fisiopatologia permanece pouco compreendida, o que limita a adoção de medidas profiláticas e terapêuticas para o manejo clínico.

Uma das maiores dificuldades reside no fato de que a etiologia do compromentimento ósseo em pacientes lúpicas é multifatorial. Deste modo, torna-se complexa a tarefa de avaliar a contribuição individual de cada fator. Nos pacientes portadores de Nefrite Lúpica deve-se atentar para um risco adicional para o comprometimento ósseo, uma vez que a proteinúria e/ou disfunção renal podem agravar a deficiência de vitamina $\mathrm{D}(7,9-11)$.

Além disso, a maior parte dos estudos disponíveis são baseados na avaliação densidade mineral óssea (DMO) através da densitometria, um método de custo relativamente baixo e amplamente disponível (12-18). Entretanto, sabemos que a redução da DMO, apesar de clinicamente relevante, pode não refletir adequamente a resistência óssea e, principalmente, não contribui para a compreensão da fisiopatologia da doença óssea $(19,20)$. 


\subsection{Inflamação e fisiopatologia do LES}

A fisiopatologia do LES é extremamente complexa. Acredita-se que fatores genéticos, ambientais, hormonais e imunoregulatórios possam atuar sequencialmente ou simultaneamente sobre o sistema imune, determinando uma perda de auto-tolerância, que culmina na ativação de células T e na geração de auto-anticorpos, imunocomplexos, e citocinas inflamatórias, responsáveis por iniciar e/ou amplificar a inflamação e o dano tecidual (1).

Vários publicações abordam os fatores envolvidos na desregulação do sistema imune observada no Lupus Eritematoso Sistêmico. De modo geral, e apesar de muitas controvérsias, acredita-se que a diferenciação a favor das respostas Th1 contribua para o desenvolvimento e/ou progressão das doenças auto-imunes, enquanto os estímulos Th2 parecem ter efeito protetor nestas patologias (21).

Como citado anteriormente, esse desbalanço imunológico é associado a múltiplas anormalidades na produção, expressão e/ou atividade de várias citocinas.

A interleucina (IL) 6 é uma proteína de fase aguda que apresenta vários efeitos sobre o sistema imunológico, dentre os quais: diferenciação, maturação e estimulação de células B; secreção de imunoglobulinas; e diferenciação de células T citotóxicas. Em modelos animais (NZB/W F1), o tratamento com IL-6 promove o desenvolvimento de uma forma severa e acelerada de glomerulonefrite membranoproliferativa. Além disso, o tratamento com anti-IL-6 ou anticorpos anti-receptor de IL-6 leva à redução da proliferação de células $\mathrm{B}$, diminuição da produção de anticorpos anti-DNA e da proteinúria, além do aumento da sobrevida dos animais (22). Estudos em humanos, por sua vez, já demonstraram níveis séricos, urinários, e expressão renal glomerular aumentada de IL-6 em pacientes portadores de LES em atividade (21-24). Além disso, é importante salientar que vários estudos clínicos evidenciaram uma correlação positiva entre os níveis de IL-6 e a atividade da doença [mensurada pelo Systemic Lupus Erythematosus Disease Activity Index (SLEDAI)] (21-24).

O Fator de Necrose Tumoral alfa (TNF- $\alpha$ ) apresenta propriedades próinflamatórias e imunoregulatórias. Contribui como fator de crescimento para linfócitos $\mathrm{B}$, além de atuar na ativação e maturação de células dendríticas e na indução de resposta de fase aguda pelos hepatócitos (com produção de IL-1 e IL-6). Apesar de algumas 
controvérsias quanto ao seu papel na fisiopatologia do LES, a correlação dos níveis de TNF- $\alpha$ com a atividade da doença, assim como sua expressão no tecido renal de pacientes acometidos já foi previamente demonstrada (23-25).

O Monocyte Chemoattractant Protein-1 (MCP-1) é um fator quimiotático para leucócitos envolvido na patogênese da injúria renal relacionada ao LES (26). Vários trabalhos recentes sugerem o papel dos níveis urinários de MCP-1 como um marcador sensível e específico de atividade renal, guardando correlação com a severidade do flare e a histologia proliferativa (27-31). 


\subsection{Comprometimento Ósseo no LES}

Como citado anteriormente, a etiologia do comprometimento ósseo em pacientes portadores de LES é multifatorial (8). Além dos fatores de risco tradicionais (tais como sexo feminino, idade superior a 65 anos, raça branca ou asiática, baixo peso corporal e tabagismo), os portadores de LES são susceptíveis a alguns fatores de risco associados à doença e/ou seu tratamento:

- Redução de atividade física decorrente do comprometimento ósteo-muscular e articular;

- Menopausa precoce (relacionada à atividade da doença e/ou uso de imunossupressores como ciclofosfamida);

- Uso de glicocorticóides;

- Redução dos níveis de vitamina $\mathrm{D}$, associado principalmente a dois fatores:

○ Fotossensibilidade e recomendações para fotoproteção;

○ Proteinúria e/ou disfunção renal associados à nefrite lúpica;

- Atividade inflamatória per se. 


\subsubsection{Glicocorticóides}

O uso de glicocorticóides têm sido extensivamente associado a redução da DMO em pacientes portadores de LES $(16,32,33)$. Na verdade, a Doença Óssea induzida por Corticóides (também denominada Osteoporose induzida por Corticóides) é considerada a causa mais comum de osteoporose secundária. Sua relevância clínica pode ser exemplificada pela alta incidência de fraturas (até 30-50\%) em pacientes submetidos ao uso crônico de corticoide $(34,35)$

A Doença Óssea induzida por Corticóides evolui caracteristicamente em duas fases. No primeiro ano, ocorre uma rápida perda de densidade mineral óssea (6-12\%), presumivelmente associada ao aumento de reabsorção óssea. Posteriormente ocorre uma fase mais lenta e progressiva (3\% por ano), na qual a redução da DMO é atribuída a uma redução na formação óssea (34-36).

Vale ressaltar que, na osteoporose induzida por corticóide, o risco de fraturas pode aumentar em até $75 \%$ nos primeiros 3 meses, habitualmente antes de uma redução expressiva da DMO (37). Acredita-se que essa particularidade possa ser atribuída, pelo menos em parte, aos efeitos dos glicocorticóides em ossos trabeculares (perda da resistência óssea) (19), alterações pouco traduzidas pela densidade mineral óssea (34, $35)$.

A dose e duração de uso necessárias para acarretar um aumento do risco de doença óssea ainda não está bem estabelecida. Na maior parte dos estudos disponíveis, são avaliados pacientes submetidos a doses diárias $\geq 7,5 \mathrm{mg} /$ dia de prednisolona (ou equivalente) por um período $\geq 3$ meses $(38,39)$. Além disso, vale ressaltar que a American College of Rheumatology, a National Osteoporosis Foundation e a Royal College of Physicians recomendam intervenções farmacológicas em pacientes expostos a glicocorticóides por pelo menos 3 meses (40-43). 


\subsubsection{Vitamina $D$}

Um dos fatores que pode contribuir para o comprometimento ósseo observado nas pacientes lúpicas é a redução dos níveis de vitamina $\mathrm{D}$.

A função primordial da vitamina D é manter níveis fisiológicos de cálcio sérico, participando, deste modo, tanto de ações metabólicas (como transdução de sinais e atividade neuromuscular), quanto no metabolismo ósseo. Seu principal mecanismo de ação é o aumento da absorção intestinal de cálcio e fósforo. Além disso, sabe-se que a vitamina D pode aumentar a expressão de RANKL (receptor ativador do fator nuclear$\kappa \mathrm{B}$ ligante), osteocalcina e fosfatase alcalina, dentre outros mediadores e citocinas (4448).

Ações não calcêmicas da vitamina $D$ sobre o sistema imune também já foram descritos em alguns modelos animais. Estudos em humanos, entretanto, têm demonstrado resultados conflitantes. Acredita-se que a forma ativa da vitamina $\mathrm{D}$ seja responsável por uma redução na resposta das células Th1 e na apresentação de antígenos pelas células dendríticas. Outro efeito descrito é o aumento da expressão de catelicidina, um peptídeo antimicrobiano importante para o sistema imune inato, com particular ação sobre o Mycobacterium tuberculosis (49).

Dentre os fatores que poderiam contribuir para a deficiência de vitamina D nas pacientes portadoras de LES podemos citar:

- Fotossensibilidade e as recomendações para fotoproteção: vale citar um estudo realizado por Ruiz-Irastorza et al em um centro da Espanha com 92 pacientes (90\% do sexo feminino e $98 \%$ da raça branca). A insuficiência e deficiência de vitamina D foram encontradas em 75 e $15 \%$ dos pacientes, respectivamente. Fotossensibilidade e fotoproteção foram significativamente associados à deficiência/insuficiência de vitamina $\mathrm{D}(50)$;

- Aumento do metabolismo ou 25-hidroxilação prejudicada induzida por drogas ou pela doença per se $(45,51)$;

- Presença de anticorpos anti-vitamina D: previamente detectados em portadores de LES e significativamente associados à anti-DNA (52). 


\subsubsection{O papel da proteinúria}

A proteinúria é um importante marcador de Nefrite Lúpica e acarreta um aumento do risco de comprometimento ósseo.

Existem alguns estudos que abordam a correlação entre proteinúria e alterações ósseas. Mittal et al publicou um estudo com 30 pacientes portadores de síndrome nefrótica (proteinúria média 7,3 g/dia). A osteomálacia foi o achado de histomorfometria mais comum $(56,7 \%)$, enquanto uma biópsia normal foi encontrada em apenas 33,3\% dos casos. A severidade da osteomalácia (determinada pelo tempo de mineralização) se correlacionou linear e significativamente com a duração e quantidade da proteinúria (53).

Outro estudo interessante foi realizado por Dias et al nesta instituição com 17 pacientes adultos portadores de glomerulopatias primárias (proteinúria $>1,5 \mathrm{~g} / \mathrm{dia}$ ) e função renal normal (Taxa de Filtração Glomerular $>55 \mathrm{ml} / \mathrm{min} / \mathrm{m}^{2}$ ) (54). Observou-se uma correlação negativa entre proteinúria e níveis de 25-hidroxivitamina $\mathrm{D}_{3}$ [25(OH)D]. Acredita-se que a perda urinária de vitamina D (ligada a sua proteína carreadora) possa ser atribuída basicamente a dois mecanismos:

- Aumento da filtração (alterações de carga e tamanho dos poros da membrana capilar glomerular);

- Reabsorção tubular inadequada (secundária a lesão tubular ou a uma competição com as proteínas de maior peso molecular).

As repercussões destas alterações foram demonstradas neste mesmo estudo por meio das biópsias ósseas dos pacientes, que evidenciaram redução da formação e aumento da reabsorção óssea (54). 


\subsubsection{Disfunção renal}

O Distúrbio Mineral e Ósseo da Doença Renal Crônica (DMO-DRC) pode ser definido como uma desordem sistêmica do metabolismo mineral e ósseo que ocorre em função da doença renal crônica (DRC) e pode se manifestar através de $(55,56)$ :

- Anormalidades do cálcio, fósforo, hormônio paratiroidiano (PTH) ou metabolismo da vitamina $\mathrm{D}$;

- Anormalidades do remodelamento, mineralização ou volume ósseo;

- Calcificações vasculares ou extra-vasculares.

Apesar de apresentar uma fisiopatologia complexa e ainda não totalmente elucidada, acredita-se que o DMO-DRC se desenvolva caracteristicamente a partir do estadio 3 da DRC (taxa de filtração glomerular $<60 \mathrm{ml} / \mathrm{min} / 1,73 \mathrm{~m}^{2}$ ), quando a habilidade renal para excreção de fósforo se encontra reduzida a ponto de resultar em um estímulo para liberação de fibroblast growth factor 23 (FGF-23) e PTH. O prejuízo a conversão de $25(\mathrm{OH}) \mathrm{D}$ em 1,25-dihidroxivitamin $\mathrm{D}_{3}\left[1,25(\mathrm{OH})_{2} \mathrm{D}\right]$ leva a redução da absorção intestinal de cálcio e estímulo adicional para a liberação de PTH. Com o tempo, ocorre uma resistência renal a ação do PTH e do FGF-23, além de uma resistência tecidual a ação da vitamina D e do PTH (55).

As anormalidades ósseas são observadas em quase todos os pacientes em terapia renal substitutiva, e na maior parte dos pacientes portadores de DRC estadios 3-5 em tratamento conservador. $\mathrm{O}$ tratamento atualmente disponível é dirigido para a correção das anormalidades bioquímicas, visando limitar suas consequências (55).

Vale a pena lembrar que, em 2002, a Kidney Disease Outcome Quality Initiative (KDOQI), publicou uma diretriz sobre DRC que compreendia sua avaliação, classificação e estratificação de risco. Desde então, o diagnóstico de DRC é baseado em três componentes: um componente anatômico ou estrutural (marcadores de dano renal), um componente funcional [baseado na Taxa de Filtração Glomerular (TFG)] e um componente temporal. Com base nessa definição, seria portador de DRC qualquer indivíduo que, independente da causa, apresentasse TFG $<60 \mathrm{~mL} / \mathrm{min} / 1,73 \mathrm{~m}^{2}$ ou a TFG > $60 \mathrm{~mL} / \mathrm{min} / 1,73 \mathrm{~m}^{2}$ associada a pelo menos um marcador de dano renal parenquimatoso 
[albuminúria, alterações do sedimento urinário, histologia renal ou estrutura renal (detectados por exame de imagem), ou ainda antecedente de transplante renal] presente há pelo menos 3 meses (57-59).

Por fim, ainda não existem estudos suficientes para determinar a relevância de eventuais alterações bioquímicas ou ósseas no contexto de uma disfunção renal aguda. 


\subsubsection{Fatores Inflamatórios}

A influência da atividade inflamatória per se sobre o status ósseo dos pacientes lúpicos começou a ganhar destaque na literatura mediante a publicação de alguns estudos que não demonstraram associação entre redução da DMO e uso de corticóide (9, 12, 13, 60-62).

Um destes estudos, desenvolvido por Almehed et al, objetivou identificar a prevalência e importância de alguns dos fatores de risco para osteoporose em pacientes lúpicos. Em uma regressão multivariada, a redução da densidade mineral óssea foi significativamente associada à idade avançada, baixo peso corpóreo, elevação de marcadores inflamatórios (velocidade de hemossedimentação, proteína C reativa) e creatinina sérica, combinação de DMARDs (drogas anti-reumáticas modificadoras da doença) e índice de dano (SLICC/ACR - Systemic Lupus International Collaborative Clinics/American College of Rheumatology - Damage Index). O uso atual ou cumulativo de glicocorticóide, no entanto, não foi relacionado à redução da densidade mineral óssea (9).

De modo análogo, Lee et al avaliou 307 pacientes lúpicas e demonstrou que a redução da DMO estava associada a presença de dano relacionado ao LES (medido pelo Systemic Lupus International Collaborating Clinics/American College of Rheumatology cumulative disease damage index - SDI), independentemente do uso de corticoide (60).

Além disso, existem relatos de redução da DMO em pacientes que nunca foram tratados com corticoides $(12,14,63)$. Um exemplo é o trabalho publicado por Sels et al. Nesta revisão de dados referentes a 61 pacientes citados previamente na literatura e que não foram tratados com glicocorticóides, observou-se uma redução significativa da densidade óssea na coluna, quadril e antebraço, sugerindo novamente que o comprometimento ósseo poderia estar relacionado à atividade da doença (63).

Mais recentemente, o trabalho desenvolvido por Borba et al com mulheres em pré-menopausa acompanhadas no Hospital São Paulo/ Universidade Federal de São Paulo abordou a correlação da atividade clínica do LES não apenas com citocinas inflamatórias, mas também com deficiência de vitamina $\mathrm{D}$ e marcadores de remodelação óssea (51). As pacientes $(n=36)$, clinicamente semelhantes aos controles, 
apresentavam em média 4-5 anos de doença e foram divididas em dois grupos de acordo com a atividade da doença [mensurada pelo Systemic Lupus Erythematosus Disease Activity Index (SLEDAI)]. O Grupo I era constituído de pacientes com maior atividade da doença (SLEDAI $\geq 12$, dose média de prednisona no último ano $=12,2 \mathrm{mg} / \mathrm{dia}$, variando entre 0 e 32,1 mg/dia). No Grupo II foram incluídas pacientes com $\mathrm{SLEDAI} \leq 3$ (dose média de prednisona no último ano =6,2 mg/dia, variando de 0 a 15,2 mg/dia). A comparação entre os grupos evidenciou que as pacientes do Grupo I (maior atividade lúpica) apresentaram níveis significativamente maiores de IL-1, IL-6 e TNFa. Além disso, este grupo foi associado aos menores níveis de $25(\mathrm{OH}) \mathrm{D}$ e osteocalcina (marcador de formação óssea). Observou-se uma correlação negativa entre osteocalcina e TNF $\alpha(\mathrm{r}=-0.428, \mathrm{p}=0.01)$, enquanto a deoxipiridinolina urinária (marcador de reabsorção óssea) se correlacionou positivamente com o SLEDAI $(r=0.063, p=0.02)$, sugerindo a influência de fatores inflamatórios no metabolismo ósseo. Não se observou correlação estatística entre os marcadores de remodelação óssea e a dose atual ou pregressa de glicocorticóides (51).

Apesar dos dados citados, ainda faltam estudos que permitam esclarecer a relação entre fatores inflamatórios e comprometimento ósseo em pacientes portadores de LES. Não são relatados na literatura protocolos que estudem biópsias ósseas (histomorfometria e imunohistoquímica) em pacientes com NL, alta atividade inflamatória, e submetidos à baixa carga de glicocorticóides. Vale citar apenas um resumo do XV Congresso Latino Americano de Nefrologia e Hipertensão, que apresenta dados de um estudo realizado em um hospital infantil do México que avaliou 30 crianças portadoras de LES (idade média de 11 anos, sendo 80\% do sexo feminino) através de exames laboratoriais e biópsias ósseas com estudo histomorfométrico. As crianças foram divididas em grupos de acordo com a exposição a tratamento imunossupressor e a presença de disfunção renal. No grupo constituído por crianças que não haviam recebido tratamento imunossupressor e não apresentavam disfunção renal $(\mathrm{n}=7$, perfazendo $23 \%$ do total), todas as crianças apresentaram biópsias sugestivas de baixo remodelamento ósseo, sugerindo novamente a influência da atividade inflamatória per se sobre a densidade mineral óssea em pacientes lúpicos (64). 


\subsection{Osteoimunologia: atividade inflamatória e comprometimento ósseo}

A interação entre os sistemas imunológico e ósseo tem sido estudado desde a década de 70. Desde então, vários trabalhos têm demonstrado que estes sistemas não só podem ser mediados por inúmeras moléculas em comum (citocinas, receptores e fatores transcricionais), como também podem interagir na própria medula óssea (65).

Em 2000, um ano após a descrição do sistema RANK (receptor ativador do fator nuclear- $\kappa \mathrm{B})$ - RANKL (receptor ativador do fator nuclear- $\kappa \mathrm{B}$ ligante), o termo Osteoimunologia foi utilizado pela primeira vez para descrever o campo interdisciplinar que estuda as interrelações entre os sistemas ósseo e imunológico.

Apesar das evidências de interação entre os sistemas imunológico e ósseo provenientes de estudos experimentais, observações in vitro (66-70), e determinados contextos clínicos (como a perda de massa óssea associada a menopausa e a hipercalciúria idiopática) $(67,70,71)$, os maiores exemplos desta interação são esperados em estados de ativação anormal e/ou prolongada do sistema imune, em doenças auto-imunes como Artrite Reumatóide, Doença Inflamatória Intestinal e LES $(7,72-76)$.

A ação da osteoprotegerina (OPG) e do sistema RANK-RANKL sobre a imunidade e regulação do metabolismo ósseo constitui uma área de crescente interesse da comunidade científica. Portanto, seguem algumas considerações a respeito deste sistema. 


\subsubsection{Osteoprotegerina e Sistema RANK-RANKL}

A osteoprotegerina (OPG) é uma glicoproteína, membro da superfamília do receptor do fator de necrose tumoral (TNF), codificada pelo cromossomo oito. Trata-se de um receptor solúvel para o RANKL, que atua competindo com o RANK. Acredita-se que tenha efeitos regulatórios sobre a maturação de células $B$ e a geração de uma

resposta humoral específica. É secretada por uma variedade de tecidos, tais como órgãos do sistema cardiovascular, pulmões, intestino, tecido hematopoiético e ossos (especificamente linhagem osteoblástica). Pode ser expressa em células B e células dendríticas. Sua produção e expressão é modulada por citocinas, hormônios e outras substâncias, tais como medicamentos usados na prática clínica (figura 1) (8, 77-79).

O RANK e o RANKL também são membros da superfamília do receptor de TNF. O RANK é expresso na superfície de osteoclastos e seus precursores, células T ativadas e células dendríticas. Seu ligante, o RANKL, é uma proteína transmembrana produzida e expressa por células da linhagem osteoblástica e células $\mathrm{T}$ ativadas. A ligação RANK-RANKL deflagra mecanismos no metabolismo ósseo e sistema imune:

- Estímulo para formação, fusão, diferenciação, ativação e sobrevivência dos osteoclastos, responsáveis pela reabsorção óssea;

- Aumento da sobrevida e da capacidade imunoestimulatória das células dendríticas, além de modular células $\mathrm{T}$ ativadas.

A expressão de RANKL por osteoblastos também pode ser regulada por várias citocinas, tais como IL-1, IL-6, IL-17 e TNF $\alpha$ (figura 1) $(65,77,78,80)$. 
Figura 1: Osteoprotegerina e sistema RANK-RANKL: relação entre mediadores inflamatórios, sistema imune e metabolismo ósseo.

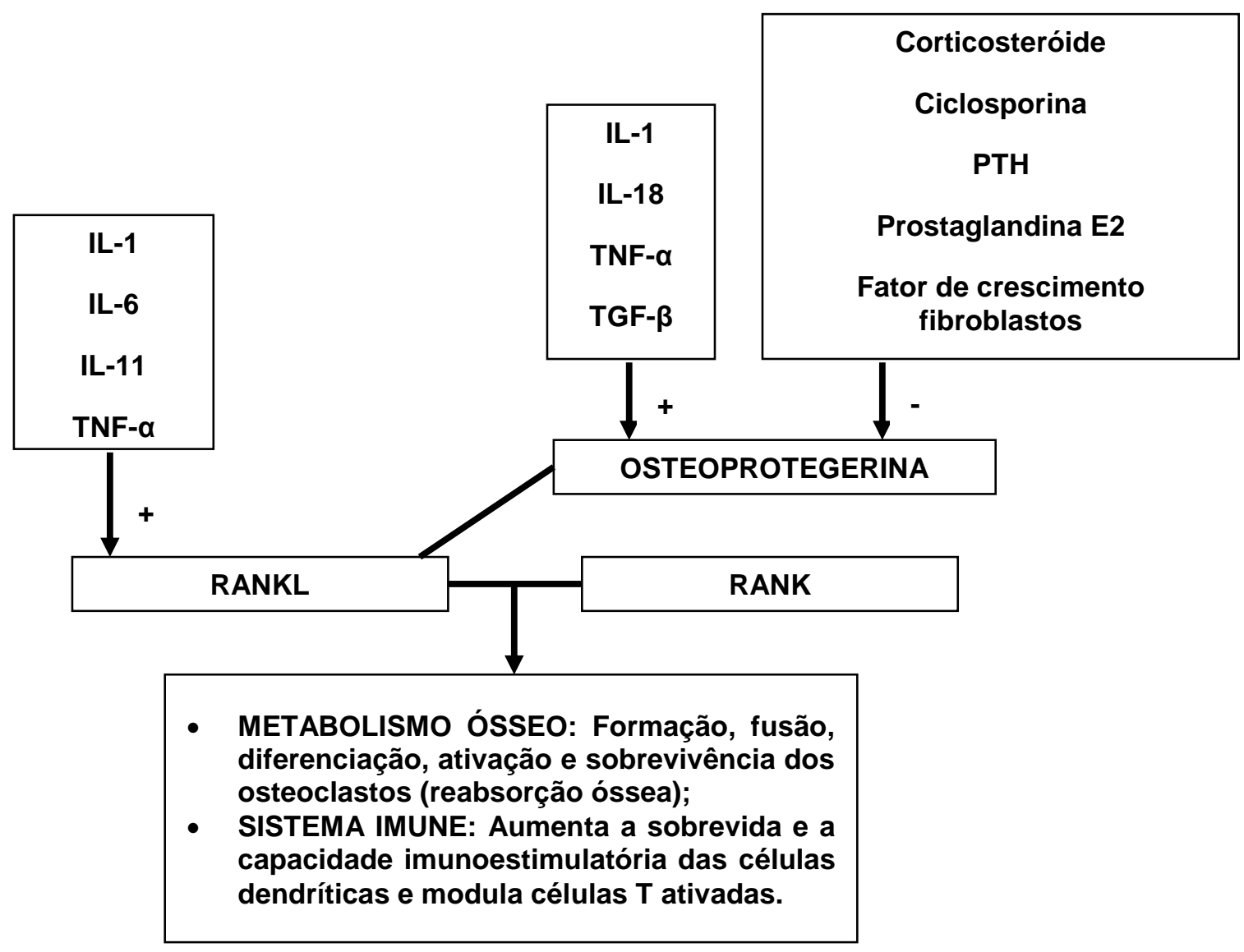

Legenda: IL ( interleucina); PTH (hormônio paratiroidiano); RANK (receptor ativador do fator nuclear- $\kappa \mathrm{B}$ ); RANKL (receptor ativador do fator nuclear- $\kappa \mathrm{B}$ ligante); TNF- $\alpha$ (fator de necrose tumoral alpha); TFG- $\beta$ (transforming growth factor beta). 
Objetivos 
O objetivo deste trabalho foi estudar, em pacientes com Nefrite Lúpica ativa de diagnóstico recente, e submetidas à baixa carga de corticóide:

- A doença óssea através de técnicas de:

○ Histomorfometria;

○ Imunohistoquímica;

- Cultura de osteoblastos.

- O estado inflamatório sistêmico/renal e suas correlações com a doença óssea.

Nossa hipótese é que estas pacientes apresentem um comprometimento ósseo precoce, possivelmente influenciado pela atividade inflamatória per se. 
Métodos 


\subsection{População estudada}

Neste estudo observacional foram incluídos pacientes do sexo feminino com diagnóstico recente ( $\leq 2$ meses) de LES $[\geq$ quatro critérios do American College of Rheumatology (ACR) (81)] e nefrite lúpica (de acordo com critérios ACR) atendidos no Hospital das Clínicas da Faculdade de Medicina da Universidade de São Paulo (FM USP) no período de dezembro de 2010 a dezembro de 2012.

Os critérios de exclusão foram: história/evidência de doença renal crônica; gestação; menopausa; uso prévio de suplementação de cálcio/vitamina D ou medicações que influenciam o metabolismo ósseo (como anticoagulantes orais $\mathrm{e}$ anticonvulsivantes); presença de doença tireoidiana.

Os critérios de inclusão e exclusão foram determinados de modo a reduzir a influência de outros fatores sabidamente associados à perda de massa óssea.

Todos os pacientes candidatos ao estudo receberam explicações e orientações sobre o protocolo e seus riscos e assinaram um termo de consentimento informado. $\mathrm{O}$ projeto foi aprovado pela Comissão de Ética para Análise de Projetos de Pesquisa (CAPPesq) da Diretoria Clínica do Hospital das Clínicas e da Faculdade de Medicina da Universidade de São Paulo ( $\left.{ }^{\circ} 0373 / 10\right)$. 


\subsection{Avaliação clínico-laboratorial}

A atividade clínica do LES foi estimada pelo SLEDAI (Systemic Lupus Erythematosus Disease Activity Index) (82).

As biópsias renais foram realizadas pelo Serviço de Nefrologia, de acordo com suas indicações e normas, independentemente deste estudo. As biópsias realizadas foram analizadas pelo Serviço de Patologia utilizando a Classificação da International Society of Nephrology (ISN)/Renal Pathology Society (83).

As pacientes foram tratadas pelo Serviço de Nefrologia do Hospital das Clínicas da FM USP de acordo com protocolos padronizados na literatura. Todas as pacientes receberam glicocorticóides desde o seu diagnóstico. A dose acumulada e tempo de exposição foram contabilizados no momento da biópsia óssea.

Os exames sumarizados abaixo são rotineiramente utilizados no manejo clínico dos pacientes e foram realizados no Laboratório Central do Hospital das Clínicas da FM USP duas a três semanas antes da biópsia óssea:

- Hemograma, uréia, creatinina, glicemia, perfil lipídico, cálcio total, cálcio iônico, fósforo, eletroforese de proteínas e fosfatase alcalina;

- Perfil imunológico (FAN, Frações do complemento C3 e C4, anti-DNA);

- $25(\mathrm{OH}) \mathrm{D}_{3}$ medido por quimioimunoensaio;

- PTH intacto medido por imunoquimioluminométrico;

- Dosagens urinárias de creatinina e proteinúria.

A taxa de filtração glomerular (TFG) foi estimada pela fórmula simplificada do MDRD (Modification of Diet in Renal Disease) (84).

Durante o período de inclusão das pacientes, amostras de sangue e urina das pacientes foram colhidas e acondicionadas a $-80^{\circ} \mathrm{C}$ no Laboratório de Investigação Médica (LIM) 16. Ao final do estudo, foram realizadas as seguintes dosagens bioquímicas:

- MCP-1 sérico e urinário (Human MCP-1 ELISA, R\&D Systems);

- IL-6 sérico (Human IL-6 ELISA, R\&D Systems); 
- TNFa sérico (Human TNFa ELISA, R\&D Systems);

- Esclerostina sérica (Human Sclerostin ELISA Kit, Quidel);

- Deoxipiridinolina sérica (Total Deoxypyridinoline ELISA, Quidel).

Os níveis urinários de MCP-1 foram normalizados para a excreção urinária de creatinina dosada na mesma amostra e expressas como pg/mg de creatinina.

O grupo controle para a análise bioquímica foi constituído por mulheres saudáveis pareadas por idade, predominantemente estudantes e funcionárias do LIM. As amostras de sangue e urina dos controles foram colhidos no final do inverno (setembro 2012), período em que são esperados os níveis mais baixos de vitamina D. Todas as pacientes e controles eram residentes permanentes da região metropolitana de São Paulo.

Além disso, as pacientes lúpicas foram comparadas a 6 pacientes do sexo feminino portadores de glomerulonefrite primária (proteinúria $>1,5 \mathrm{~g} / \mathrm{dia}$ e Taxa de Filtração Glomerular > 55ml/min $/ 1,73 \mathrm{~m}^{2}$ ), previamente estudadas pelo nosso grupo (54). 


\subsection{Biópsia Óssea}

Antes da biópsia óssea, as pacientes foram submetidas a uma marcação com tetraciclina $20 \mathrm{mg} / \mathrm{Kg} / \mathrm{dia}$ (por via oral, em duas tomadas) por três dias. Esta mesma dose foi repetida após um intervalo de dez dias. As biópsias ósseas foram realizadas entre o segundo e o sétimo dia após o final da segunda tomada de tetraciclina, sob anestesia local com lidocaína $2 \%$ e sedação com midazolan 7,5 mg intramuscular.

As biópsias foram realizadas no osso ilíaco. Inicialmente foi realizada uma incisão de aproximadamente $2 \mathrm{~cm}$ na pele e tecido subcutâneo em um ponto determinado a dois centímetros posterior e dois abaixo da crista ilíaca antero-superior. Utilizando uma trefina elétrica (Gaulthier Medical, Rochester, EUA), foram retirados fragmentos ósseos de $1,5 \mathrm{~cm}$ de comprimento.

As biópsias foram colocadas em meio de transporte [Dulbecco's Modified Eagle Medium (DMEM) suplementado com tampão HEPES $25 \mathrm{mM}$, Penicilina 250 UI, estreptomicina $250 \mu \mathrm{g} / \mathrm{mL}$ e anfotericina $3 \mu \mathrm{g} / \mathrm{mL}$ )] e levadas até o fluxo laminar, onde foram divididas em 2 fragmentos, um para a cultura de células e outro para os experimentos de histomorfometria/imunohistoquímica). 


\subsubsection{Cultura de células ósseas}

Os fragmentos destinados a cultura foram subdivididos em fragmentos menores $\left(1 \mathrm{~mm}^{3}\right)$, que foram lavados com PBS (tampão fosfato salina) para a retirada de células da medula óssea, e distribuídos em placas de Petri de poliestireno de $100 \mathrm{~mm}$ (Nunc, Ilinois, EUA) nas quais adicionamos $10 \mathrm{~mL}$ de meio de cultivo celular [DMEM, suplementados com 50 UI de penicilina, $50 \mu \mathrm{g} / \mathrm{mL}$ de estreptomicina, $2,5 \mu \mathrm{g} / \mathrm{mL}$ de anfotericina B e $20 \%$ de soro fetal bovino (SFB) (Cultilab, Campinas, Brasil)].

As placas foram mantidas a $37^{\circ} \mathrm{C}$ em estufa contendo $\mathrm{CO} 2$ a $5 \%$, tendo seu meio de cultura trocado três vezes por semana, durante aproximadamente duas semanas. Após esse período, os fragmentos foram retirados da placa de Petri, e as células mantidas sob os mesmos cuidados até atingirem confluência. A seguir, as células foram dissociadas com tripsina recombinante TrypLE ${ }^{\mathrm{TM}}$ Express (Gibco, USA) e separadas em duas alíquotas. A primeira foi semeada em placa de seis orifícios para a caracterização fenotípica das células ósseas (avaliação da capacidade de mineralização e atividade de fosfatase alcalina) $(85,86)$. A segunda foi congelada em nitrogênio líquido para posterior análise da proliferação e função celular (experimentos de incorporação pela timidina e citometria de fluxo).

Fragmentos ósseos de falecidos doadores de órgãos do sexo feminino e pareados quanto à idade, foram colhidos durante o período do estudo, submetidos ao mesmo protocolo descrito acima e utilizados como grupo-controle para os experimentos de cultura.

Ao final do estudo, as células dos pacientes e dos controles foram descongelados em banho-maria $\left(37^{\circ} \mathrm{C}\right)$ e semeadas em garrafas de $75 \mathrm{~cm}^{2}$. O meio de cultura DMEM + SFB $10 \%$ foi trocado três vezes por semana até as células atingirem nova confluência. Após serem dissociadas, as células foram utilizadas nos experimentos descritos abaixo. Vale a pena ressaltar que, uma vez que o fenótipo das células ósseas humanas tende a diminuir após múltiplas passagens (86), as células utilizadas nestes experimentos estavam em primeira ou segunda passagem. 


\subsubsection{Proliferação Celular}

As células ósseas foram semeadas em placas de 24 wells $\left(1,8 \times 10^{4}\right.$ células por well) até atingirem confluência. $\mathrm{O}$ soro fetal bovino foi então retirado do meio de cultura e o ácido ascórbico $(100 \mu \mathrm{g} / \mathrm{ml})$ foi adicionado. Após um período de 16 horas (privação), foi acrescentado $5 \mu \mathrm{Ci} / \mathrm{ml}$ de ${ }^{3} \mathrm{H}$-Timidina (Amersham Pharmacia Biotech Brasil Ltda, São Paulo, Brasil) em cada well. Após 2 horas, a timidina foi retirada, as células foram lavadas duas vezes com PBS 5 gelado $(1 \mathrm{~mL})$ e duas vezes com $1 \mathrm{~mL}$ de ácido tricloracético (TCA) $5 \%$ para a precipitação do DNA. As células foram resuspendidas com $300 \mu \mathrm{L}$ de $\mathrm{NaOH}$ 0,2N/Sarcosil 0,3\%. Alíquotas de $60 \mu \mathrm{L}$ desse homogenato foram adicionados a $3 \mathrm{~mL}$ de líquido de cintilação (com ácido acético glacial: $1,2 \mu \mathrm{L} / 3 \mathrm{~mL}$ ). Os frascos foram agitados no vortex, protegidos da luz por duas horas e em seguida analisados em contador de cintilação beta Beckman modelo LS6200 (Beckman Instruments, Palo Alto, EUA).

A contagem do controle foi realizada em $60 \mu \mathrm{L}$ de $\mathrm{NaOH} 0.2 \mathrm{~N} / \mathrm{Sarcosil} 3 \%$. Os valores desse controle foram descontados daqueles obtidos das células. Os experimentos foram realizados em triplicata e os resultados foram expressos como contagem por minuto (CPM). 


\subsubsection{Citometria de Fluxo}

Pela citometria de fluxo foram avaliadas as seguintes proteínas: fosfatase alcalina, osteocalcina e Monocyte Chemoattractant Protein-1 (MCP-1). As marcações foram realizadas nas células separadamente de acordo com os protocolos descritos a seguir.

Para avaliar a expressão da fosfatase alcalina (marcação da membrana celular), cerca de $0,5 \times 10^{6}$ células foram dispensadas em tubos próprios para citometria. As células foram incubadas por 10 minutos a $4^{\circ} \mathrm{C}$ com $10 \mu \mathrm{lde} \operatorname{IgG}$ humana $(10 \mathrm{mg} / \mathrm{mL})$, visando bloquear receptores Fc $\gamma$. As células foram lavadas duas vezes com PBS contendo $1 \%$ de BSA (albumina de soro bovino) (Sigma, St Louis, EUA) e 0,1\% de azida sódica (Sigma, St Louis, EUA), e centrifugadas por 5 minutos a $4^{\circ} \mathrm{C}(1200 \mathrm{rpm})$. A seguir, as células foram incubadas por 30 minutos a $4^{\circ} \mathrm{C}$ com anti fosfatase alcalina humana, produzida em camundongo, na concentração de $10 \mu \mathrm{g} / \mathrm{ml}$ (US Biological, MA, EUA). Como controle negativo, as células foram incubadas com anti IgG1 de camundongo (controle isotípico), por 30 minutos a $4^{\circ} \mathrm{C}$, na concentração de $10 \mu \mathrm{g} / \mathrm{ml}$ (R\&D systems Inc., MN, EUA). Em seguida, as células foram novamente lavadas duas vezes com PBS contendo $1 \%$ de BSA e $0,1 \%$ de azida sódica e centrifugadas 5 minutos a $4^{\circ} \mathrm{C}(1200 \mathrm{rpm})$. Na etapa seguinte, as células foram incubadas com $10 \mu \mathrm{l}$ de anticorpo de cabra anti-imunoglobulina de camundongo conjugado com isotiocianato de fluoresceína - GAM-FITC, na concentração de $50 \mu \mathrm{g} / \mathrm{ml}$ (Southern Biotechnology Associates, Birmingham, AL., EUA) por 30 minutos protegidas da luz. Em seguida, as células foram novamente lavadas duas vezes com PBS contendo $1 \%$ de BSA e $0,1 \%$ de azida sódica, centrifugadas por 5 minutos a $40^{\circ} \mathrm{C}(1200 \mathrm{rpm})$, fixadas com paraformaldeído a 1\% em PBS (10 mM tampão fosfato salino, $\mathrm{pH} 7,4)$, e mantidas a $4^{\circ} \mathrm{C}$, novamente protegidas da luz.

Para avaliar a expressão intracelular de osteocalcina e MCP-1, cerca de $0,5 \times 10^{6}$ células foram dispensadas em tubos para citometria. As células foram fixadas com paraformaldeído 1\% em PBS, lavadas duas vezes com tampão Hanks' balanced salt solution - HBSS, centrifugadas por 7 minutos a $4^{\circ} \mathrm{C}, 200$ x g. Após a última centrifugação, as células foram então ressuspendidas em tampão SAP $(0,1 \%$ de saponina, 0,05\% de azida sódica em tampão HBSS) e centrifugadas, uma vez, por 7 
minutos a $4^{\circ} \mathrm{C}, 200 \mathrm{x}$ g. $\mathrm{O}$ sobrenadante foi decantado e as células incubadas com anticorpo monoclonal anti osteocalcina humana conjugada com o fluorocromo ficoeritrina (OC-PE), 0,25 $\mu \mathrm{g} / \mathrm{ml}$ (R\&D systems Inc., MN, EUA) ou com anticorpo monoclonal anti MCP-1, 2,5 $\mu \mathrm{g} / \mathrm{ml}$ (R\&D systems Inc., MN, EUA), 45 minutos, a $4^{\circ} \mathrm{C}$, protegidas da luz. Após a incubação, as células foram lavadas duas vezes com tampão SAP, centrifugadas 7 minutos a $4^{\circ} \mathrm{C}, 200 \mathrm{x}$ g e o sobrenadante descartado.

As células que foram incubadas com anti OC-PE, foram ressuspendidas com PBS, mantidas a $4^{\circ} \mathrm{C}$, protegidas da luz. As células incubadas com anti MCP-1, foram novamente incubados com - GAM-FITC, na concentração de $50 \mu \mathrm{g} / \mathrm{ml}$, por 30 minutos, a $4^{\circ} \mathrm{C}$, protegidos da luz. Após essa etapa, as células foram lavadas duas vezes com tampão SAP e centrifugadas 7 minutos a $4^{\circ} \mathrm{C}, 200 \mathrm{x}$ g. O sobrenadante foi descartado e as células ressuspendidas com PBS, mantidas a $4^{\circ} \mathrm{C}$, protegidas da luz.

As células usadas como controles foram incubadas com uma proteína ( $\operatorname{IgG}$ K7.1) que não se expressa em osteoblastos. As células foram analisadas no citômetro FACScalibur (Becton Dickinson, San Diego, CA, EUA) e com o programa CellQuest ${ }^{\circledR}$ (Becton Dickinson, San Diego, CA, EUA). Os resultados foram expressos como porcentagem de células positivas $(\%)$ e intensidade média de fluorescência (IMF), descontados do controle. 


\subsubsection{Histomorfometria e imunohistoquímica}

O fragmento destinado a análise histomorfométrica e imunohistoquímica foi fixado em álcool a 70\%, desidratado em álcool 100\%, diafanizado em Tolueno e incluído em metil-metacrilato. Os blocos foram cortados em micrótomo de impacto Polycut S (Leika, Alemanha) com navalha de tungstênio obtendo-se cortes de 5 e $10 \mu \mathrm{m}$.

Os cortes de $5 \mu \mathrm{m}$ foram corados com azul de toluidina 0,1\%, pH 6,4 (Sigma Chemical, St. Louis, EUA). A análise dos parâmetros histomorfométricos estáticos foi realizada utilizando-se microscópio (Nikon, Labophot-2A), cursor, placa digitalizadora e o software Osteomeasure (Osteometrics, Inc, Atlanta, EUA). Os cortes de $10 \mu \mathrm{m}$, não corados, foram utilizados para análise das marcações pela tetraciclina (parâmetros dinâmicos), empregando-se uma fonte de luz ultravioleta.

Os parâmetros histomorfométricos foram divididos em estáticos/estruturais e dinâmicos e seguiram a nomenclatura padronizada pela American Society for Bone and Mineral Research (87), traduzida para o português, com exceção das abreviaturas.

Os parâmetros estáticos avaliados foram:

- Estruturais: volume trabecular (BV/TV) $(\%)$, espessura trabecular $(\mathrm{Tb} . \mathrm{Th})(\mu \mathrm{m})$, separação trabecular (Tb.Sp) (mm) e número de trabéculas (Tb.N) (/mm);

- Formação: volume osteóide (OV/BV) (\%), superfície osteoblástica (Ob.S/BS) (\%), espessura osteóide (O.Th) ( $\mu \mathrm{m})$ e superfície osteóide (OS/BS) (\%);

- Reabsorção: superfície de reabsorção (ES/BS) (\%) e superfície osteoclástica (Oc.S/BS) (\%).

Os parâmetros dinâmicos avaliados foram:

- Superfície mineralizante (MS/BS) (\%), taxa de aposição mineral (MAR) ( $\mu \mathrm{m} / \mathrm{dia})$, taxa de formação óssea (BFR/BS) $\left(\mu \mathrm{m}^{3} / \mu \mathrm{m}^{2} /\right.$ dia) e tempo de mineralização (MLT) (dias).

Utilizamos um método de imunohistoquímica adaptado para detecção de citocinas e proteínas no tecido ósseo calcificado (88). Cortes histológicos de $5 \mu \mathrm{m}$ do 
tecido ósseo calcificado foram submetidos inicialmente a desplastificação (remoção do metacrilato) com uma mistura de $50 \%$ de xilol e $50 \%$ de clorofórmio por 30 minutos. Em seguida as amostras foram rehidratadas com álcool em concentrações decrescentes $(100 \%, 96 \%, 70 \%$ e 50\%) por 20 segundos cada, e a uma rápida descalcificação com ácido acético a $1 \%$ por 10 minutos sob agitação. Posteriormente, o tecido foi tratado com Tween a 0,1\% em PBS por 30 minutos, seguido de peróxido de hidrogênio a 3\% em álcool metílico para bloqueio da peroxidase endógena.

Para a realização da imunohistoquímica utilizamos o kit LSAB System-HRP composto de Biotinylated Link Universal e Streptavidin-HRP (DAKO Corporation, California, EUA). Após o bloqueio da peroxidase endógena, foi utilizado o Protein Block (Dako Cytomation) para evitar marcações inespecíficas. Terminada esta etapa, os cortes foram submetidos a incubação com os seguintes anticorpos primários (12-16 horas, a $\left.4^{\circ} \mathrm{C}\right)$ :

- Osteoprotegerina 1:80 (goat monoclonal anti-human, Santa Cruz Biotechnology, CA, EUA);

- RANKL 1:150 (goat monoclonal anti-human,Santa Cruz Biotechnology, CA, EUA).

Após este período, os cortes foram incubados com os anticorpos secundários (biotinylated link). Como último passo, as lâminas foram incubadas com estreptavidina. A revelação foi realizada com a solução de AEC (3-amino-9 ethyl-carbazol). Os cortes foram contracorados com solução do hemalumbre de Mayer. Controles negativos simultâneos foram realizados em cada experimento, omitindo-se o anticorpo primário. Como controles positivos, foram utilizados amostras de pacientes com Distúrbio Mineral e Ósseo da Doença Renal Crônica (DMO-DRC) pertencentes ao banco de dados do LIM 16.

Foi realizada a contagem de osteócitos em todos os campos das biópsias (aumento de 200x). A expressão foi considerada positiva quando os osteócitos apresentavam uma coloração marrom característica. Os resultados foram expressos como a porcentagem de osteócitos positivos para cada proteína estudada em relação ao total de osteócitos de cada biópsia. 
Foram utilizados 3 grupos-controle distintos. Os parâmetros histomorfométricos estáticos e os resultados de imunohistoquímica das pacientes foram comparados aos de 15 indivíduos do sexo feminino (pareados for idade) provenientes de um banco de dados brasileiro de indivíduos normais (89). Os parâmetros dinâmicos, por sua vez, foram comparados aos de 29 indivíduos saudáveis do sexo feminino (idade média 29 anos, variando de 19 a 53 anos) (90). Adicionalmente, os parâmetros estáticos e dinâmicos das pacientes lúpicas foram comparadas aos de 6 pacientes do sexo feminino portadores de glomerulonefrite primária (proteinúria $>1,5 \mathrm{~g} /$ dia e Taxa de Filtração Glomerular $>55 \mathrm{ml} / \mathrm{min} / 1,73 \mathrm{~m}^{2}$ ), previamente estudadas pelo nosso grupo (54). 


\subsection{Dados evolutivos}

Ao final dos seis primeiros meses de acompanhamento pelo Serviço de Nefrologia, as pacientes foram classificadas de acordo com sua resposta ao tratamento imunossupressor utilizado. Esta classificação foi realizada através de exames realizados no Laboratório Central do Hospital das Clínicas da FM USP como rotina do manejo clínico das pacientes, seguindo os seguintes critérios (adaptado de KDIGO Clinical Practice Guideline for Glomerulonephritis) (91):

- Resposta Completa: retorno da creatinina sérica aos valores basais associado a queda da proteinúria para valores inferiores a $500 \mathrm{mg} / 24$ horas;

- Resposta Parcial: estabilização ( $\pm 25 \%$ do valor basal) ou melhora da creatinina associado a uma redução $\geq 50 \%$ da proteinúria em relação ao valor basal. Em casos de proteinúria basal em níveis nefróticos, a redução $\geq 50 \%$ da proteinúria em relação ao valor basal deve ser associada a níveis $<3 \mathrm{~g} / 24$ horas.

- Não-resposta: aumento > 25\% da creatinina basal ou ausência de redução da proteinúria segundo critérios descritos acima.

\subsection{Análise estatística}

Os resultados foram expressos como média ( \pm desvio padrão), mediana (quartil 2575) ou $\mathrm{n} / \%$. As análises univariadas foram realizadas utilizando-se teste t para variáveis contínuas paramétricas, teste não-paramétrico de Mann-Whitney para variáveis contínuas não-gaussianas e teste de Qui-quadrado para as variáveis categóricas. As correlações foram feitas com o teste de Spearman. A variável MCP-1 urinário foi tratada através de transformação logarítmica e utilizada como variável dependente nos modelos de regressão linear. A análise estatística foi realizada com o Software SPSS 13.0. Valores de $p$ inferiores a 0,05 foram considerados significativos. 


\subsection{Recursos financeiros}

Este estudo recebeu o auxílio da Fundação de Amparo à Pesquisa do Estado de São Paulo (FAPESP) (número 2010/15409-3), vigente de dezembro de 2010 a dezembro de 2012. 
Resultados 


\subsection{Características clínico-laboratoriais}

Durante o período de 01/12/2010 a 01/12/2012 foram incluídas 15 pacientes, cujas características clínico-laboratoriais estão descritas na tabela 1. As pacientes

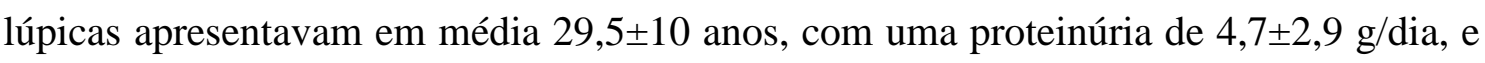
uma TFG estimada de $37(31-87) \mathrm{ml} / \mathrm{min} / 1,73 \mathrm{~m}^{2}$.

Tabela 1: Características clínico-laboratoriais das pacientes lúpicas

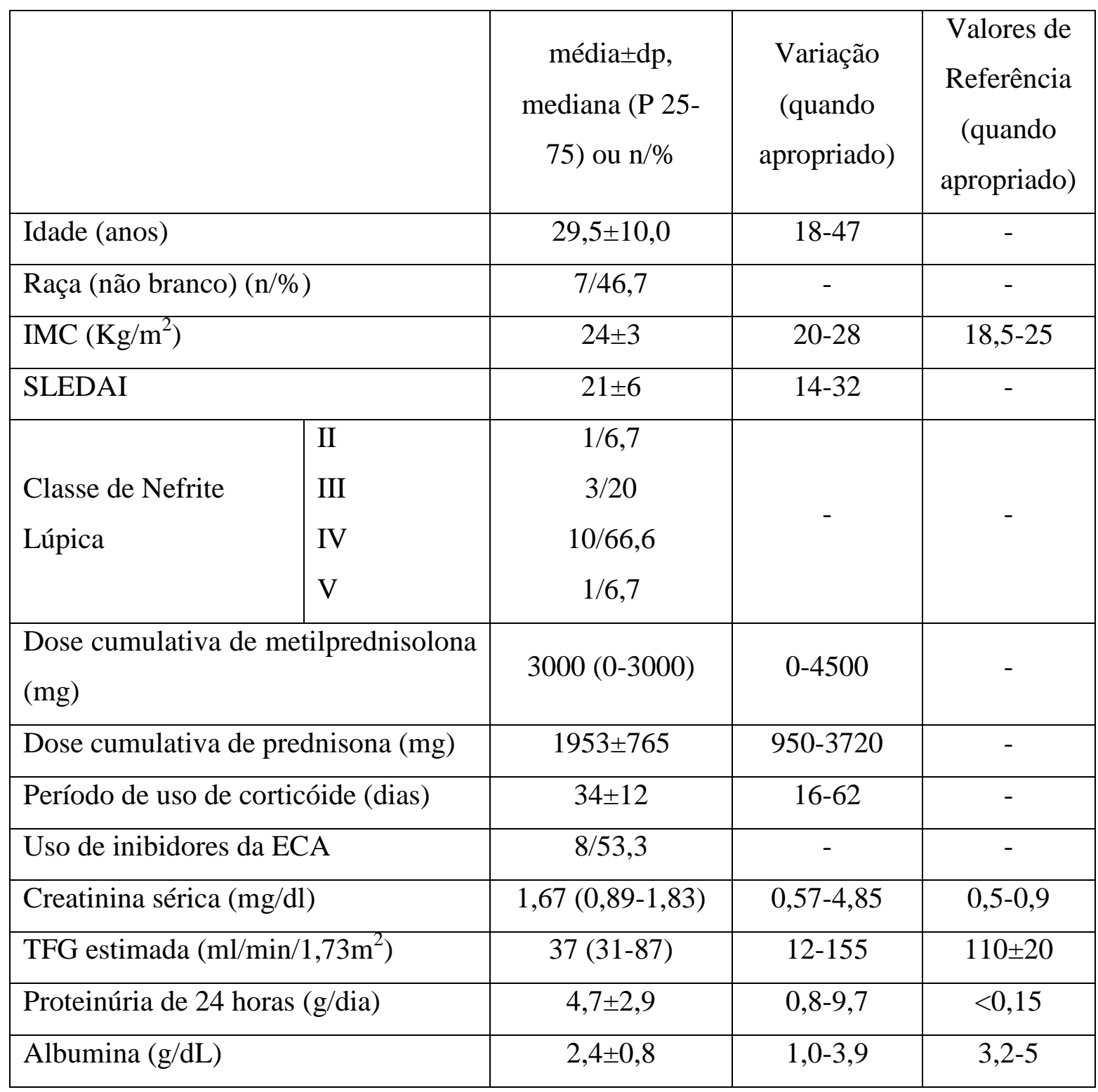


Continuação da tabela 1: Características clínico-laboratoriais das pacientes lúpicas

\begin{tabular}{|c|c|c|c|}
\hline & $\begin{array}{c}\text { média } \pm d p \\
\text { mediana }(\mathrm{P} 25-75) \\
\text { ou n/\% }\end{array}$ & $\begin{array}{c}\text { Variação } \\
\text { (quando } \\
\text { apropriado) }\end{array}$ & $\begin{array}{c}\text { Valores de } \\
\text { Referência } \\
\text { (quando } \\
\text { apropriado) }\end{array}$ \\
\hline Colesterol total (mg/dL) & $306 \pm 130$ & $152-679$ & $<200$ \\
\hline Triglicérides (mg/dL) & $268 \pm 111$ & $85-480$ & $<150$ \\
\hline $25(\mathrm{OH}) \mathrm{D}(\mathrm{ng} / \mathrm{ml})$ & $9,9 \pm 4,4$ & $4-20$ & $30-100$ \\
\hline Cálcio total (mg/dL) & $8,2 \pm 0,8$ & $6,6-9,5$ & $8,6-10,2$ \\
\hline Fósforo (mg/dL) & $4,9 \pm 1,2$ & $3,2-7,6$ & $2,7-4,5$ \\
\hline Fosfatase Alcalina (U/L) & $58(45-85)$ & $42-259$ & $35-104$ \\
\hline PTH (pg/ml) & $73(29-102)$ & 14-196 & $16-87$ \\
\hline FAN positivo & $11 / 73,3$ & - & - \\
\hline Anti-DNA positivo & $11 / 73,3$ & - & - \\
\hline C3 diminuído & $12 / 80$ & - & - \\
\hline C4 diminuído & $13 / 86,7$ & - & - \\
\hline Glicemia (mg/dL) & $83,8 \pm 15,1$ & $61-117$ & $70-100$ \\
\hline Hemoglobina (g/dL) & $9,6 \pm 1,1$ & $7,4-11,9$ & $12-16$ \\
\hline Leucócitos $\left(/ \mathrm{mm}^{3}\right)$ & $6670(4310-10520)$ & $2410-17560$ & $4000-11000$ \\
\hline Plaquetas $\left(\mathrm{mil} / \mathrm{mm}^{3}\right)$ & $203(179-410)$ & $104-572$ & $140-450$ \\
\hline
\end{tabular}

Legenda: IMC (Índice de massa corpórea); SLEDAI (Systemic Lupus Erythematosus Disease Activity Index); ECA (Enzima conversora da angiotensina I); TFG (Taxa de filtração glomerular); 25( $\mathrm{OH}) \mathrm{D}$ (25-hidroxivitamina $\mathrm{D}_{3}$ ); $\mathrm{PTH}$ (hormônio paratiroidiano); FAN (Fator anti-nuclear).

As pacientes estavam em uso de glicocorticóide por $34 \pm 12$ dias. Com relação aos outros imunossupresssores utilizados, as pacientes portadoras de nefrite lúpica proliferativa (classes III e IV) foram tratadas com pulsos mensais intravenosos de ciclofosfamida $(n=11)$ ou micofenolato via oral $(n=2)$. A paciente portadora de nefrite lúpica membranosa (classe V) foi tratada com ciclosporina via oral, enquanto a paciente portadora de nefrite lúpica classe II foi tratada com um pequeno curso de glicocorticóide isolado. 
Todas as pacientes apresentaram níveis insuficientes de vitamina D $(9,9 \pm 4,4 \mathrm{ng} / \mathrm{ml}$, variando de 4 a $20 \mathrm{ng} / \mathrm{ml})$.

Como sumarizado pela tabela 2, as pacientes lúpicas e os controles apresentavam faixa etária, raça e índice de massa corpórea (IMC) comparáveis. As pacientes lúpicas apresentavam níveis significativamente inferiores de 25(OH)D e TFG estimada. Elas também apresentaram níveis aumentados de MCP-1 sérica e urinária, IL6 , TNF $\alpha$ e deoxipiridinolina.

Tabela 2: Características clínicas e laboratoriais das pacientes portadoras de nefrite lúpica e dos controles

\begin{tabular}{|l|c|c|c|}
\hline & $\begin{array}{c}\text { Nefrite Lúpica } \\
(\mathrm{n}=15)\end{array}$ & $\begin{array}{c}\text { Controles } \\
(\mathrm{n}=15)\end{array}$ & $\mathrm{p}$ \\
\hline Idade (anos) & $29,5 \pm 10,0$ & $31,7 \pm 6,4$ & 0,25 \\
\hline Raça (não branco) (n/\%) & $7 / 46,7$ & $7 / 46,7$ & 1,00 \\
\hline IMC $\left(\mathrm{Kg} / \mathrm{m}^{2}\right)$ & $24 \pm 3$ & $24 \pm 4$ & 0,74 \\
\hline TFG estimada $\left(\mathrm{ml} / \mathrm{min} / 1,73 \mathrm{~m}^{2}\right)$ & $37(31-87)$ & $90(73-100)$ & $\mathbf{0 , 0 0 9}$ \\
\hline 25(OH)D (ng/ml) & $9,9 \pm 4,4$ & $24,3 \pm 6,2$ & $<\mathbf{0 , 0 0 1}$ \\
\hline MCP-1 sérico $(\mathrm{pg} / \mathrm{ml})$ & $18,3(16,3-39,9)$ & $11,1(10,3-13,4)$ & $<\mathbf{0 , 0 0 1}$ \\
\hline MCP-1 urinário (pg/mg Cr) & $1594(595-2447)$ & $177(113-267)$ & $<\mathbf{0 . 0 0 1}$ \\
\hline IL-6 sérico (pg/ml) & $5,8(1,9-11,3)$ & $1,2(1,1-1,4)$ & $\mathbf{0 , 0 0 2}$ \\
\hline TNF $\alpha$ sérico $(\mathrm{pg} / \mathrm{ml})$ & $9,1(8,2-19,9)$ & $5,6(5,2-6,7)$ & $<\mathbf{0 , 0 0 1}$ \\
\hline Esclerostina sérica $(\mathrm{ng} / \mathrm{ml})$ & $0,388 \pm 0,175$ & $0,357 \pm 0,102$ & 0,97 \\
\hline Deoxipiridinolina sérica (nmol/L) & $9,1(5,4-15,5)$ & $3,8(3,5-4,9)$ & $<\mathbf{0 , 0 0 1}$ \\
\hline
\end{tabular}

Legenda: IMC (Índice de massa corpórea); TFG (Taxa de filtração glomerular); 25(OH)D (25-hidroxivitamina $\left.\mathrm{D}_{3}\right)$; MCP-1 (Monocyte Chemoattractant Protein-1); IL6 (interleucina 6); TNF $\alpha$ (Fator de Necrose Tumoral $\alpha$ ).

Os níveis de 25(OH)D se correlacionaram negativamente com os de MCP-1 sérico $(\mathrm{r}=-0,53, \mathrm{p}=0,003)$ e urinário $(\mathrm{r}=-0,63, \mathrm{p}<0,001)$, IL-6 sérica $(\mathrm{r}=-0,58$, $\mathrm{p}<0,001)$, TNF $\alpha$ sérico $(\mathrm{r}=-0,53, \mathrm{p}=0,003)$ e deoxipiridinolina sérica $(\mathrm{r}=-0,59$, $\mathrm{p}<0,001$ ) (figura 2). 
Além disso, os níveis de MCP-1 urinário se correlacionaram positivamente com os de deoxipiridinolina sérica $(\mathrm{r}=0,53, \mathrm{p}=0,004)$. O SLEDAI, o período de uso e a dose cumulativa de corticosteróides não se correlacionaram com nenhuma das variáveis estudadas.

Figura 2: Correlação entre os níveis de 25(OH)D e mediadores inflamatórios
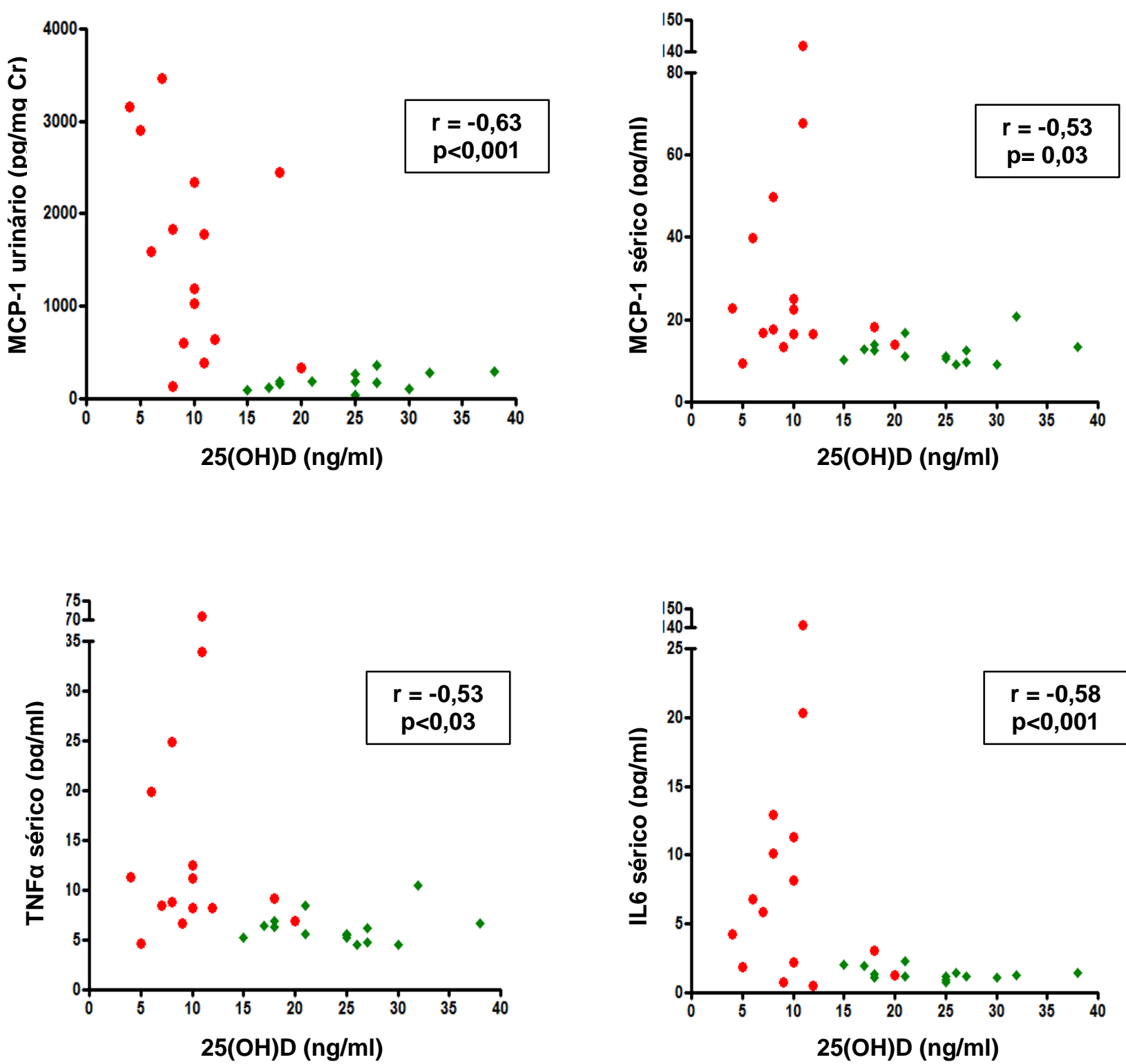

Legenda: Nos quadros estão descritos o coeficiente de correlação de Spearman e o valor de "p". Os círculos vermelhos e os losangos verdes representam as pacientes lúpicas e os controles, respectivamente. 25(OH)D (25-hidroxivitamina $\mathrm{D}_{3}$ ); MCP-1 (Monocyte Chemoattractant Protein-1); IL-6 (interleucina 6); TNF $\alpha$ (Fator de Necrose Tumoral $\alpha$ ). 
No modelo de regressão linear, observamos que a correlação entre MCP-1 urinário e 25(OH)D permaneceu após ajustes para idade, IMC e TFG estimada (beta coeff. $-0,585$, IC $95 \%-0,13$ a $-0,04, p=0,001$ ) (tabela 3 ).

Tabela 3: Modelo de regressão linear utilizando log MCP-1 urinário como variável dependente

\begin{tabular}{|l|c|c|c|c|}
\hline & Beta & Se & IC 95\% & $\mathrm{p}$ \\
\hline $25(\mathrm{OH}) \mathrm{D}(\mathrm{ng} / \mathrm{ml})$ & $-0,585$ & 0,02 & $-0,13--0,04$ & $\mathbf{0 , 0 0 1}$ \\
\hline & Beta & Se & IC 95\% & $\mathrm{p}$ \\
\hline 25(OH)D (ng/ml) & $-0,387$ & 0,02 & $-0,11--0,01$ & $\mathbf{0 , 0 3}$ \\
\hline Idade (anos) & $-0,263$ & 0,02 & $-0,09-0,01$ & 0,10 \\
\hline IMC (Kg/m2) & 0,133 & 0,06 & $-0,08-0,19$ & 0,39 \\
\hline TFG estimada $\left(\mathrm{ml} / \mathrm{min} / 1,73 \mathrm{~m}^{2}\right)$ & $-0,360$ & 0,01 & $-0,02-0,01$ & 0,04 \\
\hline
\end{tabular}

Legenda: IMC (Índice de massa corpórea); TFG (Taxa de filtração glomerular); 25(OH)D (25-hidroxivitamina $\mathrm{D}_{3}$ ); MCP-1 (Monocyte Chemoattractant Protein-1).

A comparação entre as características clínico-laboratoriais das pacientes lúpicas e com glomerulopatias primárias está descrita na tabela 4.

Observamos que as pacientes lúpicas e os controles portadores de glomerulopatias primárias apresentavam valores comparáveis de idade, IMC, proteinúria e TFG estimada. Apesar disso, as pacientes lúpicas apresentaram níveis significativamente menores de vitamina $\mathrm{D}$, o que possivelmente contribuiu para o aumento dos níveis de PTH. 
Tabela 4: Características clínico-laboratoriais das pacientes lúpicas e dos controles portadores de glomerulopatias primárias

\begin{tabular}{|l|c|c|c|}
\hline & $\begin{array}{c}\text { Nefrite Lúpica } \\
(\mathrm{n}=15)\end{array}$ & $\begin{array}{c}\text { Pacientes com } \\
\text { Glomerulopatias } \\
\text { Primárias (n=6) }\end{array}$ & $\mathrm{p}$ \\
\hline Idade $($ anos) & $29,5 \pm 10,0$ & $33,5 \pm 5,3$ & 0,42 \\
\hline IMC (Kg/m $\left.{ }^{2}\right)$ & $24 \pm 3$ & $24 \pm 2$ & 0,65 \\
\hline Proteinuria de 24 horas (g/dia) & $4,7 \pm 2,9$ & $5,6 \pm 3,3$ & 0,68 \\
\hline Albumina (g/dL) & $2,4 \pm 0,8$ & $2,1 \pm 0,9$ & 0,57 \\
\hline Cálcio total (mg/dL) & $8,2 \pm 0,8$ & $8,2 \pm 0,7$ & 0,91 \\
\hline Fósforo (mg/dL) & $4,9 \pm 1,2$ & $4,4 \pm 0,6$ & 0,30 \\
\hline Creatinina (mg/dL) & $1,67(0,89-1,83)$ & $0,85(0,7-1,0)$ & 0,06 \\
\hline TFG estimada (ml/min/1,73m $\left.{ }^{2}\right)$ & $37(31-87)$ & $85(63-116)$ & 0,12 \\
\hline $25(\mathrm{OH}) \mathrm{D}(\mathrm{ng} / \mathrm{ml})$ & $9,9 \pm 4,4$ & $18,4 \pm 11,1$ & $\mathbf{0 , 0 4 5}$ \\
\hline PTH (pg/ml) & $73(29-102)$ & $19(10-26)$ & $\mathbf{0 , 0 0 3}$ \\
\hline
\end{tabular}

Legenda: IMC (Índice de massa corpórea); TFG (Taxa de filtração glomerular); 25(OH)D (25-hidroxivitamina $\left.\mathrm{D}_{3}\right)$; PTH (hormônio paratiroidiano). 


\subsection{Biópsias ósseas}

Todas as biópsias ósseas transcorreram sem intercorrências. Não observamos efeitos adversos, a exceção de discreta dor local (tratada com analgésicos simples). As biópsias apresentaram uma área de 9.2-54.0 $\mathrm{mm}^{2}$, sendo que apenas 3 amostras apresentaram uma área $<30 \mathrm{~mm}^{2}$.

\subsubsection{Cultura de células ósseas}

Não obtivemos células ósseas a partir dos fragmentos de 5 pacientes. Quando comparamos os parâmetros clínico-laboratoriais e histomorfométricos destas pacientes com os das pacientes cujos fragmentos liberaram células ósseas, não encontramos diferença significativa.

Durante o período do estudo, foram colhidos fragmentos ósseos de 9 falecidos doadores de órgãos do sexo feminino. Tratavam-se de vítimas de acidente vascular encefálico hemorrágico e sem comorbidades relatadas. Este grupo-controle apresentava idade, IMC e TFG estimada semelhantes as pacientes lúpicas (tabela 5).

Os resultados dos experimentos de cultura de células ósseas estão sumarizados na tabela 5. Não observamos diferença significativa entre pacientes e controles na proliferação de osteoblastos medida pela incorporação pela timidina.

Nos experimentos de citometria de fluxo, as células ósseas de ambos grupos apresentaram uma alta expressão de fosfatase alcalina e uma baixa expressão de osteocalcina. Os osteoblastos das pacientes lúpicas apresentavam uma maior expressão de MCP-1 quando comparado aos controles $(32,0 \pm 9,1$ vs 22,9 $\pm 5,3 \mathrm{IMF}, \mathrm{p}=0,01)$ (figura $3)$.

Com relação a porcentagem de células positivas, observamos que as pacientes lúpicas apresentaram uma maior população de células osteocalcina positivas $(12,25 \pm 7,13$ vs 4,66 $\pm 3,69 \%$, $\mathrm{p}=0,007)$ (tabela 5). 
Tabela 5: Características clínico-laboratoriais e resultados dos experimentos de cultura (proliferação celular e citometria de fluxo) nas pacientes lúpicas e controles

\begin{tabular}{|c|c|c|c|}
\hline & $\begin{array}{l}\text { Nefrite Lúpica } \\
\qquad(\mathrm{n}=10)\end{array}$ & $\begin{array}{c}\text { Controles } \\
\quad(n=9)\end{array}$ & $\mathrm{p}$ \\
\hline \multicolumn{4}{|c|}{ CARACTERÍSTICAS CLÍNICO-LABORATORIAIS } \\
\hline Idade (anos) & $33 \pm 10,5$ & $38,3 \pm 9,5$ & 0,39 \\
\hline $\operatorname{IMC}\left(\mathrm{Kg} / \mathrm{m}^{2}\right)$ & $24,3 \pm 3,6$ & $26,2 \pm 5,8$ & 0,44 \\
\hline TFG estimada $\left(\mathrm{ml} / \mathrm{min} / 1,73 \mathrm{~m}^{2}\right)$ & $62,6 \pm 50$ & $91,4 \pm 61,9$ & 0,27 \\
\hline \multicolumn{4}{|l|}{ PROLIFERAÇÃO CELULAR } \\
\hline Incorporação pela timidina (CPM) & $82,22 \pm 48,43$ & $56,06 \pm 23,73$ & 0,21 \\
\hline \multicolumn{4}{|l|}{ CITOMETRIA DE FLUXO } \\
\hline MCP-1 (\%) & $95,1 \pm 2,3$ & $92,9 \pm 4,3$ & 0,24 \\
\hline MCP-1 (IMF) & $32,0 \pm 9,1$ & $22,9 \pm 5,3$ & $\mathbf{0 , 0 1}$ \\
\hline Osteocalcina $(\%)$ & $12,25 \pm 7,13$ & $4,66 \pm 3,69$ & $\mathbf{0 , 0 0 7}$ \\
\hline Osteocalcina (IMF) & $1,77 \pm 0,61$ & $1,63 \pm 0,50$ & 0,63 \\
\hline Fosfatase alcalina (\%) & $49,8 \pm 17,2$ & $40,5 \pm 15,1$ & 0,22 \\
\hline Fosfatase alcalina (IMF) & $20,9 \pm 12,7$ & $16,3 \pm 10,9$ & 0,33 \\
\hline
\end{tabular}

Legenda: IMC (Índice de massa corpórea); TFG (Taxa de filtração glomerular); MCP-1 (Monocyte Chemoattractant Protein-1); CPM (contagem por minuto); IMF (intensidade média de fluorescência); \% (porcentagem de células positivas). 
Figura 3: Expressão de MCP-1 pela citometria de fluxo em células ósseas de pacientes lúpicas (A) e controles (B)
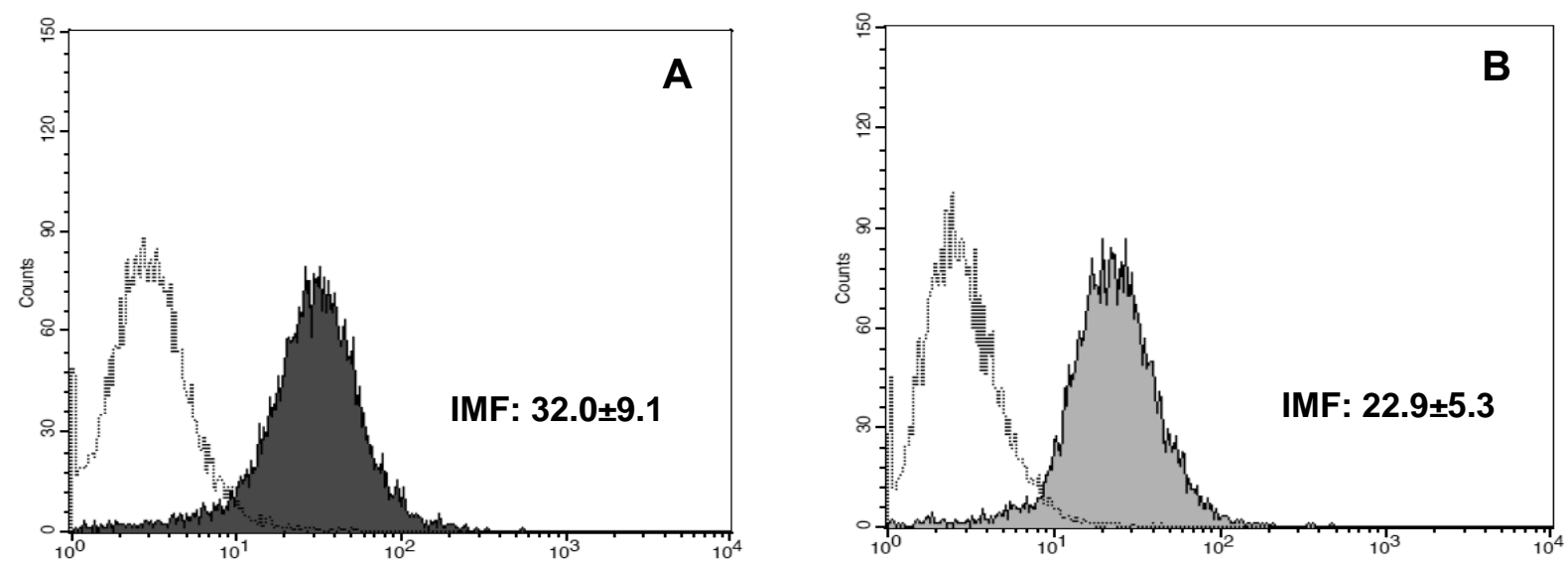

Legenda: Os dados descritos representam a média \pm desvio padrão da intensidade média de fluorescência (IMF) obtida nos grupos. Os osteoblastos das pacientes lúpicas (A) apresentavam uma maior expressão de MCP-1 quando comparado aos controles (B). 


\subsubsection{Histomorfometria}

Os resultados da análise histomorfométrica dos pacientes e controles estão descritos na tabela 6. Não observamos alterações significativas entre os grupos nos parâmetros estruturais (figura 4).

Observamos que as pacientes lúpicas apresentaram valores significativamente inferiores de três parâmetros de formação óssea [o volume (OV/BV), a espessura (O.Th) e a superfície osteóide (OS/BS)]. Além disso, detectamos também uma redução em dois parâmetros de mineralização óssea [a superfície mineralizante (MS/BS) e a taxa de formação óssea (BFR/BS)]. Por fim, as pacientes apresentavam um aumento significativo da reabsorção óssea (ES/BS) e da superfície osteoclástica (Oc.S/BS) (tabela 6) (figura 5).

Figura 4: Aspecto histológico do tecido ósseo de paciente lúpica (A) e de individuo controle (B)
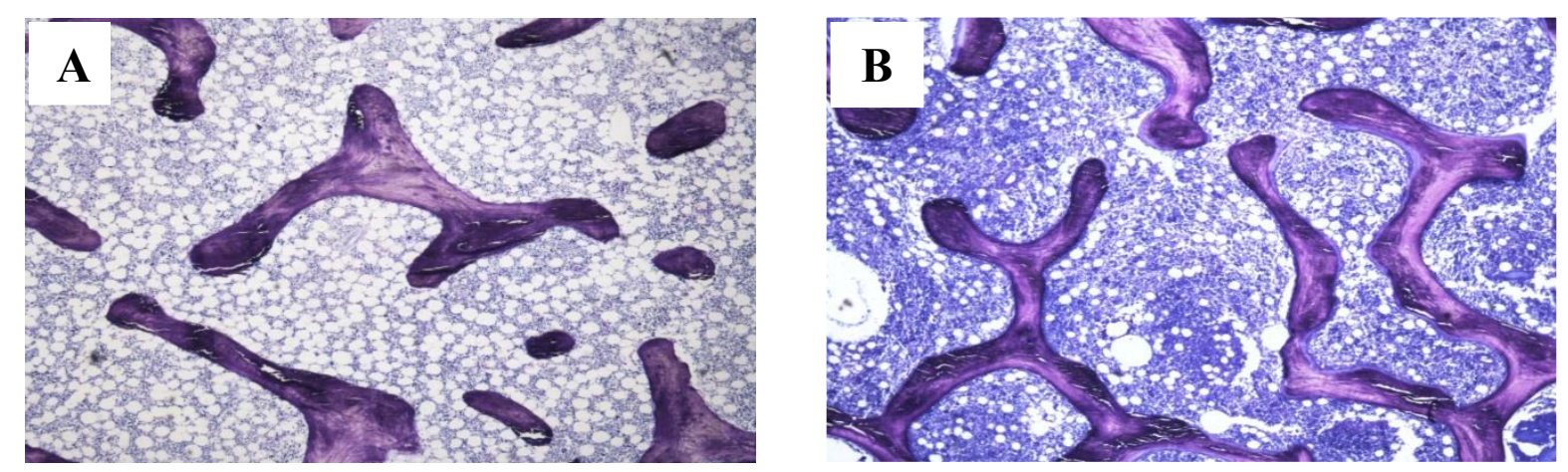

Legenda: Não observamos diferenças significativas entre os parâmetros estruturais de pacientes lúpicas (A) e controles pareados por idade (B) (Cortes de $5 \mu \mathrm{m}$ de osso não descalcificado, coloração azul de toluidina) (Aumento de 40X). 
Tabela 6: Parâmetros histomorfométricos das pacientes portadoras de nefrite lúpica e controles

\begin{tabular}{|c|c|c|c|}
\hline & $\begin{array}{l}\text { Nefrite lúpica } \\
\qquad(\mathrm{n}=15)\end{array}$ & $\begin{array}{l}\text { Controles } \\
(\mathrm{n}=15)^{(89)}\end{array}$ & $\mathrm{p}$ \\
\hline Idade (anos) & $29,5 \pm 10,0$ & $29,3 \pm 9,0$ & 0,90 \\
\hline \multicolumn{4}{|l|}{ ESTRUTURAIS } \\
\hline $\mathrm{BV} / \mathrm{TV}(\%)$ & $26,0 \pm 6,8$ & $26,4 \pm 5,0$ & 0,98 \\
\hline Tb.Th $(\mu \mathrm{m})$ & $130,7 \pm 23,7$ & $122,8 \pm 21,2$ & 0,49 \\
\hline Tb.Sp $(\mu \mathrm{m})$ & $390,4 \pm 110,9$ & $346,8 \pm 63,2$ & 0,42 \\
\hline Tb.N (/mm) & $1,99 \pm 0,39$ & $2,15 \pm 0,32$ & 0,22 \\
\hline \multicolumn{4}{|l|}{ FORMAÇ̃̃O } \\
\hline OV/BV (\%) & $0,19(0,08-0,38)$ & $1,63(1,10-2,96)$ & $<0,001$ \\
\hline Ob.S/BS (\%) & $0,68(0,20-2,65)$ & $0,80(0,20-2,66)$ & 0,69 \\
\hline O.Th $(\mu \mathrm{m})$ & $2,85 \pm 1,04$ & $11,4 \pm 2,1$ & $<0,001$ \\
\hline OS/BS (\%) & $3,6(2,1-8,9)$ & $8,9(7,2-16,5)$ & $\mathbf{0 , 0 3}$ \\
\hline \multicolumn{4}{|l|}{ MINERALIZAÇÃ ${ }^{*}$} \\
\hline MS/BS (\%) & $2,2 \pm 1,6$ & $12,0 \pm 5,0$ & $<0,001$ \\
\hline MAR $(\mu \mathrm{m} / \mathrm{dia})$ & $0,44 \pm 0,23$ & $0,64 \pm 0,10$ & 0,41 \\
\hline $\mathrm{BFR} / \mathrm{BS}\left(\mu \mathrm{m}^{3} / \mu \mathrm{m}^{2} / \mathrm{dia}\right)$ & $0,01 \pm 0,01$ & $0,07 \pm 0,03$ & $<0,001$ \\
\hline MLT (dias) & $28,8 \pm 12,8$ & $23,7 \pm 2,7$ & 0,71 \\
\hline \multicolumn{4}{|l|}{$R E A B S O R C \tilde{A} O$} \\
\hline ES/BS (\%) & $9,78(5,02-11,80)$ & $2,00(1,30-3,30)$ & $<0,001$ \\
\hline Oc.S/BS (\%) & $0,54(0,19-0,69)$ & $0,02(0-0,10)$ & $<0,001$ \\
\hline
\end{tabular}

Legenda: (BV/TV) volume trabecular; (Tb.Th) espessura trabecular; (Tb.Sp) separação trabecular; (Tb.N) número de trabéculas; (OV/BV) volume osteóide; (Ob.S/BS) superfície osteoblástica; (O.Th) espessura osteóide; (OS/BS) superfície osteóide; (MS/BS) superfície mineralizante; (MAR) taxa de aposição mineral; (BFR/BS) taxa de formação óssea; (MLT) tempo de mineralização; (ES/BS) superfície de reabsorção; (Oc.S/BS) superfície osteoclástica. *Os parâmetros dinâmicos das portadoras de nefrite lúpica foram comparados aos de 29 indivíduos saudáveis do sexo feminino (idade média 29 anos, variando de 19 a 53 anos) (91). 
Figura 5: Aspecto histológico do tecido ósseo de pacientes lúpicas $(\mathrm{A}, \mathrm{C})$ e de individuo saudável (B) (250X)
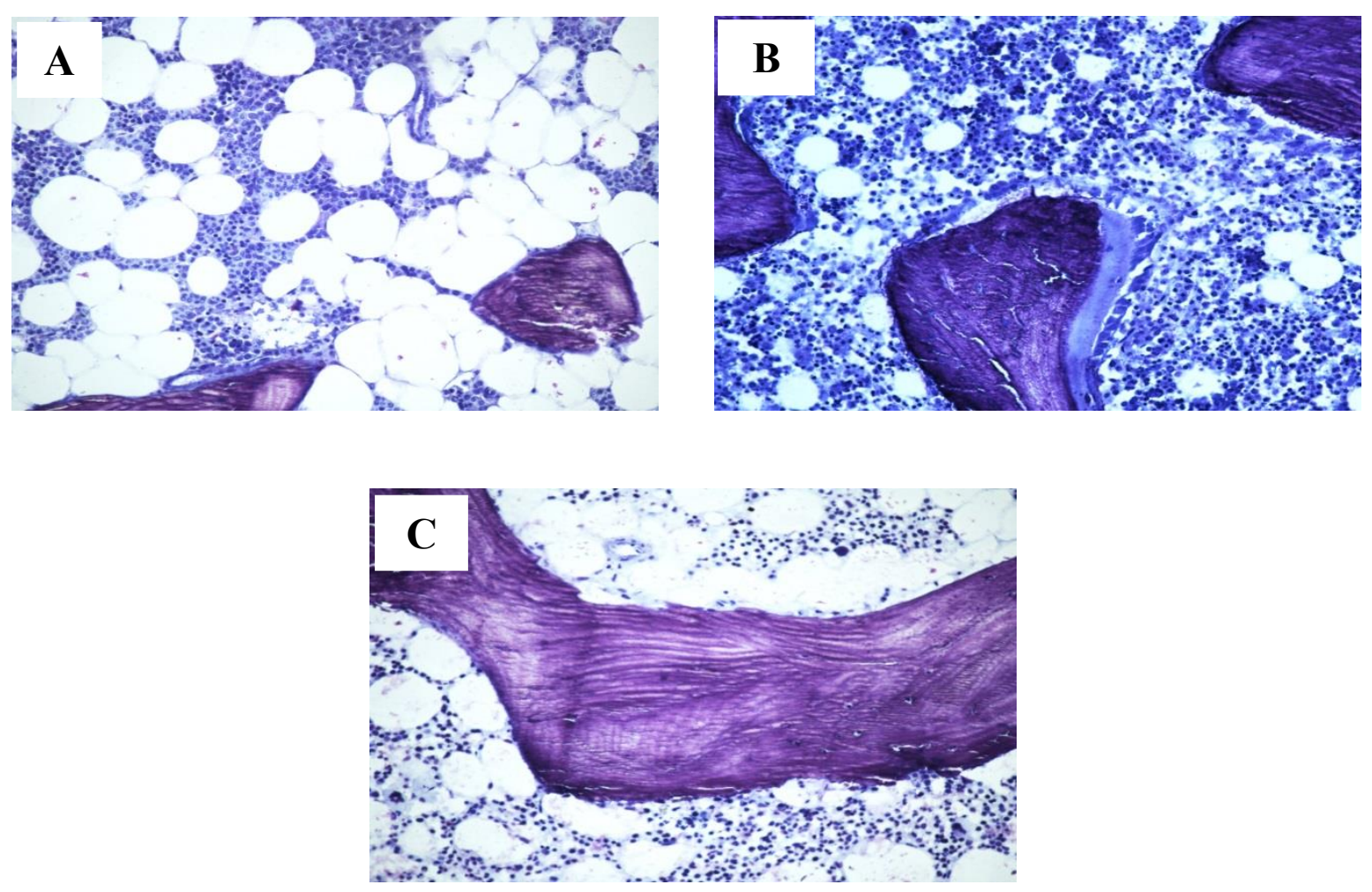

Legenda: Um menor volume, espessura e superfície osteóide foram observados em pacientes lúpicas (A) quando comparados aos controles (B). Área de reabsorção óssea em trabécula óssea em uma paciente lúpica (C) (Cortes de $5 \mu \mathrm{m}$ de osso não descalcificado, em azul de toluidina) (Aumento de 250X).

A comparação entre os parâmetros histomorfométricos das pacientes e controles portadores de glomerulopatias primárias está sumarizada na tabela 7. Os resultados se assemelham aos observados mediante a comparação das pacientes com controles normais. Não observamos alterações significativas nos parâmetros estruturais. As pacientes lúpicas apresentaram valores significativamente inferiores de espessura osteoide (O.Th), superfície mineralizante (MS/BS) e taxa de formação óssea (BFR/BS), além de uma maior reabsorção óssea (ES/BS) e superfície osteoclástica (Oc.S/BS). 
Tabela 7: Parâmetros histomorfométricos das pacientes lúpicas e controles portadores de glomerulopatias primárias

\begin{tabular}{|c|c|c|c|}
\hline & $\begin{array}{l}\text { Nefrite Lúpica } \\
\qquad(\mathrm{n}=15)\end{array}$ & $\begin{array}{c}\text { Pacientes com } \\
\text { glomeulopatias } \\
\text { primárias }(n=6){ }^{(54)}\end{array}$ & $\mathrm{p}$ \\
\hline \multicolumn{4}{|l|}{ ESTRUTURAIS } \\
\hline $\mathrm{BV} / \mathrm{TV}(\%)$ & $26,0 \pm 6,8$ & $22,1 \pm 6,7$ & 0,35 \\
\hline Tb.Th $(\mu \mathrm{m})$ & $130,7 \pm 23,7$ & $126,6 \pm 36,4$ & 0,59 \\
\hline Tb.Sp (mm) & $390,4 \pm 110,9$ & $468,0 \pm 139,7$ & 0,12 \\
\hline Tb.N (/mm) & $1,99 \pm 0,39$ & $1,76 \pm 0,45$ & 0,16 \\
\hline \multicolumn{4}{|l|}{ 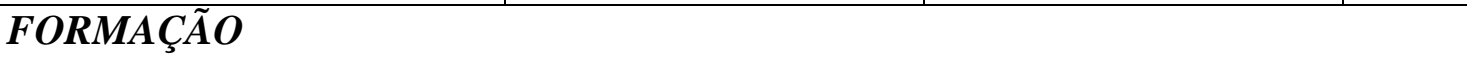 } \\
\hline OV/BV (\%) & $0,19(0,08-0,38)$ & $0,33(0,13-1,11)$ & 0,44 \\
\hline Ob.S/BS (\%) & $0,68(0,20-2,65)$ & $0,47(0,35-2,58)$ & 0,76 \\
\hline O.Th $(\mu \mathrm{m})$ & $2,85 \pm 1,04$ & $7,1 \pm 4,2$ & $\mathbf{0 , 0 2}$ \\
\hline OS/BS (\%) & $3,6(2,1-8,9)$ & $3,9(1,7-10,8)$ & 0,88 \\
\hline \multicolumn{4}{|l|}{ MINERALIZAÇÃO } \\
\hline MS/BS (\%) & $2,2 \pm 1,6$ & $4,2 \pm 3,5$ & 0,16 \\
\hline MAR $(\mu \mathrm{m} /$ dia $)$ & $0,44 \pm 0,23$ & $0,62 \pm 0,21$ & 0,09 \\
\hline $\mathrm{BFR} / \mathrm{BS}\left(\mu \mathrm{m}^{3} / \mu \mathrm{m}^{2} / \mathrm{dia}\right)$ & $0,006(0,002-0,010)$ & $0,021(0,008-0,045)$ & $\mathbf{0 , 0 1}$ \\
\hline MLT (dias) & $28,8 \pm 12,8$ & $15,1 \pm 8,8$ & 0,03 \\
\hline \multicolumn{4}{|l|}{$R E A B S O R C \tilde{A} O$} \\
\hline ES/BS (\%) & $9,78(5,02-11,80)$ & $2,55(0,90-3,88)$ & 0,001 \\
\hline Oc.S/BS (\%) & $0,54(0,19-0,69)$ & $0,21(0-0,33)$ & 0,04 \\
\hline
\end{tabular}

Legenda: (BV/TV) volume trabecular; (Tb.Th) espessura trabecular; (Tb.Sp) separação trabecular; (Tb.N) número de trabéculas; (OV/BV) volume osteóide; (Ob.S/BS) superfície osteoblástica; (O.Th) espessura osteóide; (OS/BS) superfície osteóide; (MS/BS) superfície mineralizante; (MAR) taxa de aposição mineral; (BFR/BS) taxa de formação óssea; (MLT) tempo de mineralização; (ES/BS) superfície de reabsorção; (Oc.S/BS) superfície osteoclástica. 


\subsubsection{Imunohistoquímica}

Os resultados da expressão das proteínas estudadas por imunohistoquímica estão descritos na tabela 8 e nas figuras 6 e 7 . Observamos que as pacientes lúpicas apresentavam uma menor expressão de osteoprotegerina e uma maior expressão de RANKL quando comparadas aos controles.

Tabela 8: Expressão de osteoprotegerina e RANKL em biópsias ósseas de pacientes portadoras de nefrite lúpica e controles

\begin{tabular}{|l|c|c|c|}
\hline & Nefrite lúpica $(\mathrm{n}=15)$ & ${\text { Controles }(\mathrm{n}=15)^{(89)}}^{(2)}$ & $\mathrm{p}$ \\
\hline Osteoprotegerina (\%) & $0,61 \pm 0,82$ & $1,08 \pm 0,50$ & $\mathbf{0 , 0 0 3}$ \\
\hline RANKL (\%) & $1,76 \pm 0,92$ & $0,41 \pm 0,28$ & $<\mathbf{0 , 0 0 1}$ \\
\hline
\end{tabular}

Legenda: RANKL (Receptor ativador do fator nuclear- $\kappa$ B ligante)

Figura 6: Expressão de osteoprotegerina em biópsias ósseas de pacientes com nefrite lúpica (A) e de indivíduos controles (B)
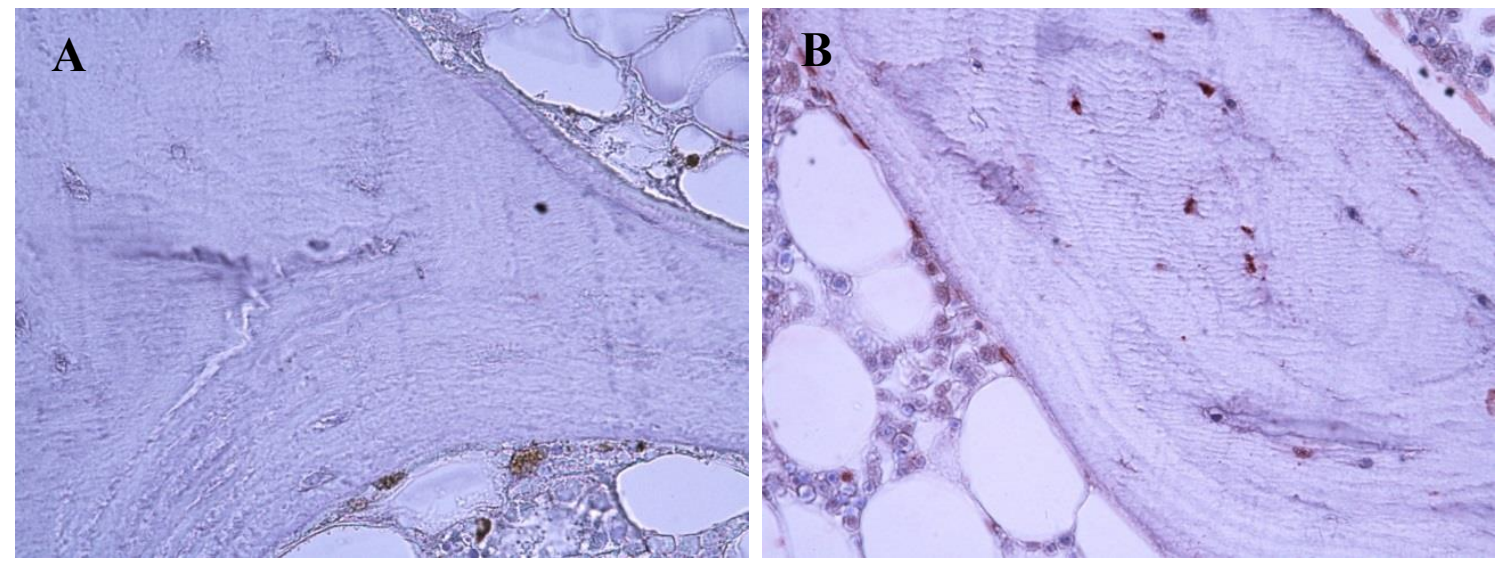

Legenda: A marcação positiva é identificada por uma coloração marrom característica. As pacientes lúpicas (A) apresentaram uma menor expressão de osteoprotegerina quando comparados aos controles (B) (Aumento de 200X). 
Figura 7: Expressão de RANKL em biópsias ósseas de paciente com nefrite lúpica (A) e de individuos controles (B)
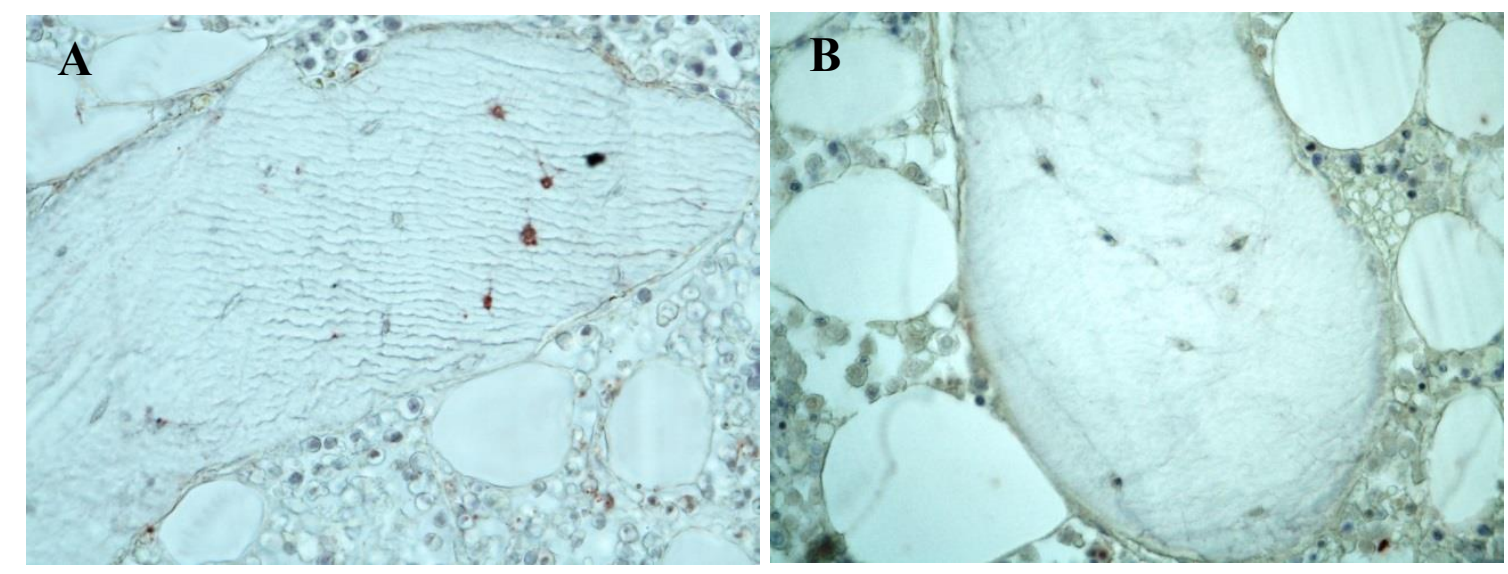

Legenda: A marcação positiva é identificada por uma coloração marrom característica. As pacientes lúpicas (A) apresentaram uma maior expressão de RANKL (Receptor ativador do fator nuclear- $\kappa \mathrm{B}$ ligante) quando comparados aos controles (B) (Aumento de 200X).

\subsection{Dados evolutivos}

Após seis meses de tratamento (período de indução), 7 pacientes $(46,6 \%)$ apresentaram uma resposta completa, $4(26,7 \%)$ apresentaram uma resposta parcial e 4 $(26,7 \%)$ não apresentaram resposta.

Apenas uma paciente estava em terapia renal substitutiva. Considerando as outras 14 pacientes estudadas, a creatinina média foi de $0,97 \pm 0,38 \mathrm{mg} / \mathrm{dl}$, com uma proteinúria de $0,86(0,21-3,39)$. Observamos um aumento significativo da TFG estimada das pacientes quando comparada aos valores basais [81(49-121) vs 37(31-87) $\left.\mathrm{ml} / \mathrm{min} / 1,73 \mathrm{~m}^{2}, \mathrm{p}=0,002\right]$. 


\section{Discussão}


Nosso estudo mostrou que pacientes com diagnóstico recente de Nefrite Lúpica apresentavam valores signficativamente inferiores de volume (OV/BV), espessura (O.Th) e superfície osteóide (OS/BS), sugerindo uma menor formação óssea. Detectamos também que estas pacientes apresentavam uma menor superfície mineralizante (MS/BS) e taxa de formação óssea (BFR/BS), sugerindo um comprometimento da mineralização óssea. Além disso, as pacientes portadoras de NL apresentavam um aumento da superfície de reabsorção (ES/BS) e da superfície osteoclástica (Oc.S/BS), sugerindo uma maior reabsorção óssea. Em função do limitado período de exposição aos glicocorticóides ( $\leq 3$ meses), acreditamos que estes achados não podem ser atribuídos a estas medicações.

Níveis insuficientes de vitamina $\mathrm{D}$ foram observados em todos os nossos pacientes $(9,9 \pm 4,4 \mathrm{ng} / \mathrm{ml}$, variando de 4 a 20$)$, sendo provavelmente um dos fatores associados ao comprometimento ósseo. A principal função da forma ativa da vitamina D (1,25-dihidroxivitamina $\left.\mathrm{D}_{3}\right)$ para a mineralização óssea é manter níveis adequados de cálcio e fósforo. Além disso, níveis insuficientes de vitamina D levam a redução da absorção intestinal de cálcio, redução dos níveis séricos de cálcio e, consequentemente, a síntese e liberação de PTH pelas glândulas paratireóides (hiperparatiroidismo secundário). O PTH não só aumenta a reabsorção tubular de cálcio, como também estimula a formação de osteoclastos, favorecendo a reabsorção óssea $(45,46)$.

A redução dos níveis de vitamina $\mathrm{D}$ em pacientes lúpicos tem sido relacionada a vários fatores. Como citado anteriormente, Ruiz-Irastorza et al demonstraram que a fotosensibilidade e a fotoproteção eram preditores de insuficiência e deficiência de vitamina D (OR 3,5 e 5,7, respectivamente) (50). No entanto, vale a pena ressaltar que as amostras de sangue e urina das nossas pacientes haviam sido colhidas ao diagnóstico. Deste modo, as pacientes ainda não haviam sido orientadas quanto a necessidade de evitar a exposição solar.

O envolvimento renal também tem sido associado a um maior risco para deficiência de vitamina $\mathrm{D}$ em pacientes lúpicos $(10,11)$. A redução dos níveis de 1,25dihidroxivitamina D3 observada no contexto de uma disfunção renal crônica tem sido atribuída a dois mecanismos fisiopatológicos: a limitação da quantidade disponível de $1 \alpha$-hidroxilase e a supressão da ação da mesma pelo aumento dos níveis de FGF-23 (92). Entretanto, a relevância destes mecanismos no contexto de uma injúria renal aguda não está bem estabelecido, e a redução da TFG basal das pacientes estudadas não pode 
ser atribuída a disfunção renal crônica. Pelo contrário, os dados evolutivos reiteram que esta redução da TFG provavelmente estava relacionada a uma injúria renal aguda associada a atividade lúpica.

A proteinúria também está associada a redução dos níveis de vitamina D. Como relatado anteriormente, acredita-se que isso ocorra em função da perda urinária do complexo vitamina D - proteína carreadora $(45,93,94)$, podendo afetar significativamente o metabolismo ósseo $(53,54,95)$. Entretando, quando comparadas a portadoras de glomerulopatias primárias com faixa etária, IMC, TFG estimada e proteinúria similares (54), as pacientes lúpicas apresentaram valores significativamente menores de vitamina $\mathrm{D}(9.9 \pm 4.4$ vs $18.4 \pm 11.1 \mathrm{ng} / \mathrm{ml}, \mathrm{p}=0.04)$, provavelmente contribuindo para o aumentos dos níveis de PTH 73 (29-102) vs 19 (10-26) pg/ml, $\mathrm{p}=0.003$ ]. Esses resultados reforçam a hipótese de que outros fatores, além da proteinúria e da disfunção renal, podem influenciar os níveis de vitamina $\mathrm{D}$ das pacientes lúpicas.

Por fim, observamos que os níveis de $25(\mathrm{OH}) \mathrm{D}$ se correlacionaram negativamente com todos os mediadores inflamatórios estudados (IL-6, TNFa, and MCP-1). A correlação negativa entre 25(OH)D e MCP-1 urinário, em especial, persistiu mesmo após ajustes para idade, IMC e TFG estimada. A correlação negativa entre a vitamina $\mathrm{D}$ e a atividade lúpica já foi demonstrada em vários trabalhos utilizando índices de atividade da doença, tais como o SLEDAI e o Physicians' Global Assessment $(51,96,97)$, reforçando a hipótese de que a vitamina D possa exercer importantes efeitos imunomodulatórios.

Além disso, os níveis de MCP-1 urinário se correlacionaram positivamente com os de deoxipiridinolina, um marcador de reabsorção óssea. Como esperado, as pacientes portadoras de NL apresentaram níveis aumentados de MCP-1, sérico e urinário, IL-6 sérico e TNF $\alpha$ sérico, considerados marcadores de atividade lúpica.

As células obtidas dos fragmentos ósseos das pacientes e controles apresentaram uma alta expressão de fosfatase alcalina e uma baixa expressão de osteocalcina, sugerindo um fenótipo de pré-osteoblastos. Apesar de não termos observado diferença na proliferação celular in vitro, as células ósseas provenientes das pacientes lúpicas apresentaram uma maior expressão de MCP-1. Esta citocina inflamatória, largamente implicada na fisiopatologia do LES, já foi identificada como um importante mediador na comunicação entre osteoblastos e osteoclastos, afetando diretamente o 
remodelamento ósseo. O MCP-1 é produzido pelos osteoblastos e, em resposta ao RANKL, pode ser expresso por precursores de osteoclastos, recrutando monócitos e outros precursores de osteoclastos (98-101). A expressão de MCP-1 já foi detectada em sítios de erupção dentária, metástases ósseas e Artrite Reumatóide, sendo regulada por outras citocinas inflamatórias, como TNFa e IL-1b, além de hormônios como o PTH (99, 100, 102-105). Deste modo, acreditamos que o aumento da expressão de MCP-1 associada a atividade lúpica pode influenciar a atividade osteoclástica, resultando em uma maior reabsorção óssea.

A interação entre os sistemas imunológico e ósseo também foi demonstrada pelos experimentos de imunohistoquímica. Observamos que as pacientes lúpicas apresentavam uma menor expressão de osteoprotegerina e uma maior expressão de RANKL quando comparadas aos controles, sugerindo que essas proteínas possam estar envolvidas na ativação dos osteoclastos, e consequentemente aumento da reabsorção óssea detectada na análise histomorfométrica. Como mencionado anteriormente, o sistema OPG/RANK/RANKL, composto por membros da superfamília do TNF, é uma via final de sinalização envolvida na regulação da reabsorção óssea. O RANKL é uma proteína transmembrana produzida por células da linhagem osteoblástica e células $\mathrm{T}$ ativadas. Além dos efeitos imunomodulatórios, a ligação do RANKL ao seu receptor RANK estimula a formação, fusão, diferenciação, ativação e sobrevida de osteoclastos, levando a aumento da reabsorção óssea. É importante lembrar que a expressão de RANKL pode ser aumentada por várias citocinas inflamatórias, tais como IL-1, IL-6, IL-17 e TNF $\alpha(65,77,78,80)$. A osteoprotegerina (OPG), por sua vez, atua como um inibidor solúvel que previne a ligação do RANKL ao RANK, reduzindo a diferenciação e ativação dos osteoclastos, e promovendo a apoptose dos mesmos $(77,78)$.

Nosso estudo apresenta várias limitações. Não obtivemos células ósseas a partir dos fragmentos de 5 pacientes. A comparação dos parâmetros clínico-laboratoriais e histomorfométricos destas pacientes com os das pacientes cujos fragmentos liberaram células ósseas não evidenciou diferenças significativas. Atribuímos este resultado ao reduzido número de pacientes em cada grupo (5 versus 10), e acreditamos que a não obtenção de células ósseas ocorreu em função de características próprias dessas pacientes que ainda não foram elucidadas. A possibilidade de eventual erro no processamento do material foi considerada improvável, uma vez que a rotina de 
processamento dos fragmentos ósseos está bem estabelecida e é praticada frequentemente no Laboratório de Investigação Médica (LIM) 16.

Também não foi possível detectar alterações significativas entre os parâmetros estruturais das pacientes lúpicas e controles. Em função das alterações detectadas na formação, mineralização e reabsorção óssea, acreditamos que este resultado provavelmente ocorreu devido ao pequeno tempo transcorrido entre o diagnóstico e a realização de biopsia óssea. Vale a pena lembrar que este tempo foi definido em função do nosso objetivo principal: detectar alterações precoces do metabolismo ósseo, que não pudessem ser justificadas pelo uso de corticoesteróides, e que provavelmente estivessem relacionados a atividade lúpica.

Apesar do reduzido número de pacientes, nosso estudo demonstrou que pacientes com diagnóstico recente de NL apresentam um significativo comprometimento ósseo, que provavelmente é influenciado pela insuficiência de vitamina D e por fatores inflamatórios. Neste contexto, a suplementação terapêutica de vitamina $\mathrm{D}$ está recomendada, apesar de que ainda restam controvérsias com relação a dose e aos níveis desejáveis. Também restam dúvidas quanto aos efeitos imunomodulatórios da vitamina D $(96,106,107)$. Outras possibilidades de tratamento seriam medicações anti-reabsortivas ou ainda o denosumab, um anticorpo monoclonal humano contra RANKL. Esta medicação tem sido utilizada com sucesso para aumentar a densidade mineral óssea e reduzir o risco de fraturas em mulheres com osteoporose pós-menopausa (108-110). Além disso, já exitem protocolos de estudo avaliando o uso de denosumab em diversas situações clínicas, tais como Artrite Reumatóide, tumores primários e metástases ósseas (111-113). No entanto, outros estudos são necessários para avaliar sua eficácia e segurança em pacientes portadores de LES. 


\subsection{Considerações Finais}

Pacientes com diagnóstico recente de Nefrite Lúpica apresentaram um significativo comprometimento ósseo, marcado por uma redução da formação e mineralização, associado a um aumento da reabsorção óssea, mesmo quando comparadas a portadoras de glomerulopatias primárias com TFG e proteinúria semelhantes.

Todas as pacientes estudadas apresentaram níveis insuficientes de vitamina D, provavelmente contribuindo para o comprometimento ósseo observado.

Os níveis de MCP-1 urinário se correlacionaram negativamente com os de $25(\mathrm{OH}) \mathrm{D}$ e positivamente com os de deoxipiridinolina, sugerindo que fatores inflamatórios possam contribuir para a insuficiência de vitamina $\mathrm{D}$ e a reabsorção óssea.

A expressão óssea aumentada de RANKL e reduzida de OPG, assim como o aumento da expressão de MCP-1 pelas células ósseas das pacientes lúpicas, reiteram a hipótese de que a inflamação per se possa influenciar a reabsorção óssea observada nestas pacientes.

A melhor compreensão da fisiopatologia do comprometimento ósseo no LES e NL é importante para aperfeiçoar a abordagem profilática e terapêutica destas pacientes, que estão sob risco adicional diante do uso de imunossupressores e do desenvolvimento de disfunção renal. 
Conclusões 
Pacientes com diagnóstico recente de nefrite lúpica ( $\leq 2$ meses), submetidas a um reduzido tempo de exposição e carga cumulativa de corticóide, apresentaram:

- Análise histomorfométrica: uma diminuição da formação e mineralização óssea, associado a um aumento da reabsorção óssea;

- Imunohistoquímica: uma expressão óssea aumentada de RANKL e reduzida de OPG;

- Citometria de fluxo das células ósseas: um aumento da expressão de MCP-1;

- Análise laboratorial (estado inflamatório x comprometimento ósseo):

○ níveis insuficientes de vitamina D;

- correlação negativa entre a vitamina D e os mediadores inflamatórios (MCP-1, IL-6 e TNF $\alpha$ );

○ correlação positiva entre MCP-1 urinário e deoxipiridinolina. 
Referências Bibliográficas 
1. Tsokos GC. Systemic lupus erythematosus. The New England journal of medicine. 2011 Dec 1;365(22):2110-21. PubMed PMID: 22129255.

2. Contreras G, Roth D, Pardo V, Striker LG, Schultz DR. Lupus nephritis: a clinical review for practicing nephrologists. Clinical nephrology. 2002 Feb;57(2):95107. PubMed PMID: 11863131.

3. Fiehn C, Hajjar Y, Mueller K, Waldherr R, Ho AD, Andrassy K. Improved clinical outcome of lupus nephritis during the past decade: importance of early diagnosis and treatment. Annals of the rheumatic diseases. 2003 May;62(5):435-9. PubMed PMID: 12695156. Pubmed Central PMCID: 1754523.

4. Bono L, Cameron JS, Hicks JA. The very long-term prognosis and complications of lupus nephritis and its treatment. QJM : monthly journal of the Association of Physicians. 1999 Apr;92(4):211-8. PubMed PMID: 10396609.

5. Uramoto KM, Michet CJ, Jr., Thumboo J, Sunku J, O'Fallon WM, Gabriel SE. Trends in the incidence and mortality of systemic lupus erythematosus, 1950-1992. Arthritis and rheumatism. 1999 Jan;42(1):46-50. PubMed PMID: 9920013.

6. Waldman M, Appel GB. Update on the treatment of lupus nephritis. Kidney international. 2006 Oct;70(8):1403-12. PubMed PMID: 16929249.

7. Bultink IE. Osteoporosis and fractures in systemic lupus erythematosus. Arthritis care \& research. 2012 Jan;64(1):2-8. PubMed PMID: 22213721.

8. Lee C, Ramsey-Goldman R. Osteoporosis in systemic lupus erythematosus mechanisms. Rheumatic diseases clinics of North America. 2005 May;31(2):363-85, viii. PubMed PMID: 15922151.

9. Almehed K, Forsblad d'Elia H, Kvist G, Ohlsson C, Carlsten H. Prevalence and risk factors of osteoporosis in female SLE patients-extended report. Rheumatology. 2007 Jul;46(7):1185-90. PubMed PMID: 17500075.

10. Bogaczewicz J, Sysa-Jedrzejowska A, Arkuszewska C, Zabek J, Kontny E, McCauliffe D, et al. Vitamin D status in systemic lupus erythematosus patients and its association with selected clinical and laboratory parameters. Lupus. 2012 Apr;21(5):477-84. PubMed PMID: 22065093.

11. Sumethkul K, Boonyaratavej S, Kitumnuaypong T, Angthararuk S, Cheewasat P, Manadee N, et al. The predictive factors of low serum 25-hydroxyvitamin D and vitamin D deficiency in patients with systemic lupus erythematosus. Rheumatology international. 2013 Jun;33(6):1461-7. PubMed PMID: 23179257. 
12. Kalla AA, Fataar AB, Jessop SJ, Bewerunge L. Loss of trabecular bone mineral density in systemic lupus erythematosus. Arthritis and rheumatism. 1993 Dec;36(12):1726-34. PubMed PMID: 8250992.

13. Formiga F, Moga I, Nolla JM, Pac M, Mitjavila F, Roig-Escofet D. Loss of bone mineral density in premenopausal women with systemic lupus erythematosus. Annals of the rheumatic diseases. 1995 Apr;54(4):274-6. PubMed PMID: 7763104. Pubmed Central PMCID: 1005573.

14. Houssiau FA, Lefebvre C, Depresseux G, Lambert M, Devogelaer JP, Nagant de Deuxchaisnes C. Trabecular and cortical bone loss in systemic lupus erythematosus. British journal of rheumatology. 1996 Mar;35(3):244-7. PubMed PMID: 8620299.

15. Gilboe IM, Kvien TK, Haugeberg G, Husby G. Bone mineral density in systemic lupus erythematosus: comparison with rheumatoid arthritis and healthy controls. Annals of the rheumatic diseases. 2000 Feb;59(2):110-5. PubMed PMID: 10666165. Pubmed Central PMCID: 1753071.

16. Lakshminarayanan S, Walsh S, Mohanraj M, Rothfield N. Factors associated with low bone mineral density in female patients with systemic lupus erythematosus. The Journal of rheumatology. 2001 Jan;28(1):102-8. PubMed PMID: 11196509.

17. Redlich K, Ziegler S, Kiener HP, Spitzauer S, Stohlawetz P, Bernecker P, et al. Bone mineral density and biochemical parameters of bone metabolism in female patients with systemic lupus erythematosus. Annals of the rheumatic diseases. 2000 Apr;59(4):308-10. PubMed PMID: 10733481. Pubmed Central PMCID: 1753103.

18. Sinigaglia L, Varenna M, Binelli L, Zucchi F, Ghiringhella D, Gallazzi M, et al. Determinants of bone mass in systemic lupus erythematosus: a cross sectional study on premenopausal women. The Journal of rheumatology. 1999 Jun;26(6):1280-4. PubMed PMID: 10381043.

19. Seeman E, Delmas PD. Bone quality--the material and structural basis of bone strength and fragility. The New England journal of medicine. 2006 May 25;354(21):2250-61. PubMed PMID: 16723616.

20. Weinstein RS, Wan C, Liu Q, Wang Y, Almeida M, O'Brien CA, et al. Endogenous glucocorticoids decrease skeletal angiogenesis, vascularity, hydration, and strength in aged mice. Aging cell. 2010 Apr;9(2):147-61. PubMed PMID: 20047574. Pubmed Central PMCID: 2858771. 
21. Lourenco EV, La Cava A. Cytokines in systemic lupus erythematosus. Current molecular medicine. 2009 Apr;9(3):242-54. PubMed PMID: 19355907. Pubmed Central PMCID: 3589140.

22. Chun HY, Chung JW, Kim HA, Yun JM, Jeon JY, Ye YM, et al. Cytokine IL-6 and IL-10 as biomarkers in systemic lupus erythematosus. Journal of clinical immunology. 2007 Sep;27(5):461-6. PubMed PMID: 17587156.

23. Davas EM, Tsirogianni A, Kappou I, Karamitsos D, Economidou I, Dantis PC. Serum IL-6, TNFalpha, p55 srTNFalpha, p75srTNFalpha, srIL-2alpha levels and disease activity in systemic lupus erythematosus. Clinical rheumatology. 1999;18(1):1722. PubMed PMID: 10088943.

24. Sabry A, Sheashaa H, El-Husseini A, Mahmoud K, Eldahshan KF, George SK, et al. Proinflammatory cytokines (TNF-alpha and IL-6) in Egyptian patients with SLE: its correlation with disease activity. Cytokine. 2006 Aug;35(3-4):148-53. PubMed PMID: 17027280.

25. Aringer M, Smolen JS. The role of tumor necrosis factor-alpha in systemic lupus erythematosus. Arthritis research \& therapy. 2008;10(1):202. PubMed PMID: 18226185. Pubmed Central PMCID: 2374473.

26. Rovin BH. The chemokine network in systemic lupus erythematous nephritis. Frontiers in bioscience : a journal and virtual library. 2008;13:904-22. PubMed PMID: 17981599.

27. Rovin BH, Song H, Birmingham DJ, Hebert LA, Yu CY, Nagaraja HN. Urine chemokines as biomarkers of human systemic lupus erythematosus activity. Journal of the American Society of Nephrology : JASN. 2005 Feb;16(2):467-73. PubMed PMID: 15601744.

28. Rovin BH, Zhang X. Biomarkers for lupus nephritis: the quest continues. Clinical journal of the American Society of Nephrology : CJASN. 2009 Nov;4(11):1858-65. PubMed PMID: 19729426.

29. Kiani AN, Johnson K, Chen C, Diehl E, Hu H, Vasudevan G, et al. Urine osteoprotegerin and monocyte chemoattractant protein-1 in lupus nephritis. The Journal of rheumatology. 2009 Oct;36(10):2224-30. PubMed PMID: 19648301.

30. Li Y, Tucci M, Narain S, Barnes EV, Sobel ES, Segal MS, et al. Urinary biomarkers in lupus nephritis. Autoimmunity reviews. 2006 Jul;5(6):383-8. PubMed PMID: 16890891. 
31. Rosa RF, Takei K, Araujo NC, Loduca SM, Szajubok JC, Chahade WH. Monocyte chemoattractant-1 as a urinary biomarker for the diagnosis of activity of lupus nephritis in Brazilian patients. The Journal of rheumatology. 2012 Oct;39(10):1948-54. PubMed PMID: 22942263.

32. Kipen Y, Buchbinder R, Forbes A, Strauss B, Littlejohn G, Morand E. Prevalence of reduced bone mineral density in systemic lupus erythematosus and the role of steroids. The Journal of rheumatology. 1997 Oct;24(10):1922-9. PubMed PMID: 9330933.

33. Jardinet D, Lefebvre C, Depresseux G, Lambert M, Devogelaer JP, Houssiau FA. Longitudinal analysis of bone mineral density in pre-menopausal female systemic lupus erythematosus patients: deleterious role of glucocorticoid therapy at the lumbar spine. Rheumatology. 2000 Apr;39(4):389-92. PubMed PMID: 10817771.

34. Canalis E, Mazziotti G, Giustina A, Bilezikian JP. Glucocorticoid-induced osteoporosis: pathophysiology and therapy. Osteoporosis international : a journal established as result of cooperation between the European Foundation for Osteoporosis and the National Osteoporosis Foundation of the USA. 2007 Oct;18(10):1319-28. PubMed PMID: 17566815.

35. Mazziotti G, Giustina A, Canalis E, Bilezikian JP. Glucocorticoid-induced osteoporosis: clinical and therapeutic aspects. Arquivos brasileiros de endocrinologia e metabologia. 2007 Nov;51(8):1404-12. PubMed PMID: 18209880.

36. LoCascio V, Bonucci E, Imbimbo B, Ballanti P, Adami S, Milani S, et al. Bone loss in response to long-term glucocorticoid therapy. Bone and mineral. 1990 Jan;8(1):39-51. PubMed PMID: 2306553.

37. Van Staa TP, Laan RF, Barton IP, Cohen S, Reid DM, Cooper C. Bone density threshold and other predictors of vertebral fracture in patients receiving oral glucocorticoid therapy. Arthritis and rheumatism. 2003 Nov;48(11):3224-9. PubMed PMID: 14613287.

38. Silverman SL, Lane NE. Glucocorticoid-induced osteoporosis. Current osteoporosis reports. 2009 Mar;7(1):23-6. PubMed PMID: 19239826.

39. van Staa TP, Leufkens HG, Cooper C. The epidemiology of corticosteroidinduced osteoporosis: a meta-analysis. Osteoporosis international : a journal established as result of cooperation between the European Foundation for Osteoporosis and the 
National Osteoporosis Foundation of the USA. 2002 Oct;13(10):777-87. PubMed PMID: 12378366.

40. Weinstein RS. Clinical practice. Glucocorticoid-induced bone disease. The New England journal of medicine. 2011 Jul 7;365(1):62-70. PubMed PMID: 21732837.

41. Grossman JM, Gordon R, Ranganath VK, Deal C, Caplan L, Chen W, et al. American College of Rheumatology 2010 recommendations for the prevention and treatment of glucocorticoid-induced osteoporosis. Arthritis care \& research. 2010 Nov;62(11):1515-26. PubMed PMID: 20662044.

42. National osteoporosis foundation's clinican's guide to the prevention and treatment of osteoporosis. Washington, DC. National Osteoporosis Foundation, 2009.

43. Bone and Tooth Society of Great Britain. Guidelines on the prevention and treatment of glucocorticoid-induced osteoporosis. London: Royal Collage of Physicians, 2003.

44. Guyton AC, Hall, JE. Hormonio paratiroideo, calcitonina, metabolismo do calcio e do fosforo, vitamina D, ossos e dentes. In: Tratado de Fisiologia Medica. 9 ed: Guanabara Koogan; 1997. p. 759-70.

45. Holick MF. Vitamin D deficiency. The New England journal of medicine. 2007 Jul 19;357(3):266-81. PubMed PMID: 17634462.

46. Holick MF, Garabedian M. Vitamin D: Photobiology, Metabolism, Mechanism of Action, and Clinical Applications. In: 2006 American Society for Bone and Mineral Research2006. p. 106-14.

47. Holick MF. Sunlight and vitamin D for bone health and prevention of autoimmune diseases, cancers, and cardiovascular disease. The American journal of clinical nutrition. 2004 Dec;80(6 Suppl):1678S-88S. PubMed PMID: 15585788.

48. Khazai N, Judd SE, Tangpricha V. Calcium and vitamin D: skeletal and extraskeletal health. Current rheumatology reports. 2008 Apr;10(2):110-7. PubMed PMID: 18460265. Pubmed Central PMCID: 2669834.

49. Liu PT, Stenger S, Li H, Wenzel L, Tan BH, Krutzik SR, et al. Toll-like receptor triggering of a vitamin D-mediated human antimicrobial response. Science. 2006 Mar 24;311(5768):1770-3. PubMed PMID: 16497887.

50. Ruiz-Irastorza G, Egurbide MV, Olivares N, Martinez-Berriotxoa A, Aguirre C. Vitamin D deficiency in systemic lupus erythematosus: prevalence, predictors and 
clinical consequences. Rheumatology. 2008 Jun;47(6):920-3. PubMed PMID: 18411213.

51. Borba VZ, Vieira JG, Kasamatsu T, Radominski SC, Sato EI, Lazaretti-Castro M. Vitamin D deficiency in patients with active systemic lupus erythematosus. Osteoporosis international : a journal established as result of cooperation between the European Foundation for Osteoporosis and the National Osteoporosis Foundation of the USA. 2009 Mar;20(3):427-33. PubMed PMID: 18600287.

52. Carvalho JF, Blank M, Kiss E, Tarr T, Amital H, Shoenfeld Y. Anti-vitamin D, vitamin D in SLE: preliminary results. Annals of the New York Academy of Sciences. 2007 Aug;1109:550-7. PubMed PMID: 17785344.

53. Mittal SK, Dash SC, Tiwari SC, Agarwal SK, Saxena S, Fishbane S. Bone histology in patients with nephrotic syndrome and normal renal function. Kidney international. 1999 May;55(5):1912-9. PubMed PMID: 10231454.

54. Dias CB, Dos Reis LM, Caparbo VF, Graciolli FG, Moyses RM, Barros RT, et al. Decreased in vitro osteoblast proliferation and low turnover bone disease in nonuremic proteinuric patients. Kidney international. 2007 Mar;71(6):562-8. PubMed PMID: 17228363.

55. Kidney Disease: Improving Global Outcomes. KDIGO clinical practice guideline for the diagnosis, evaluation, prevention, and treatment of Chronic Kidney Disease-Mineral and Bone Disorder (CKD-MBD). Kidney international Supplement. 2009 Aug(113):S1-130. PubMed PMID: 19644521.

56. Diretrizes Brasileiras de Pratica Clinica para o Disturbio Mineral e Osseo na Doença Renal Cronica. Jornal Brasileiro de Nefrologia. 2008;30 (Supl 2):2-3.

57. Bastos MGK, Gianna Mastroianni. Doença renal cronica: importancia do diagnostico precoce, encaminhamento imediato e abordagem interdisciplinar estruturada para melhora do desfecho em pacientes ainda nåo submetidos a dialise. Jornal Brasileiro de Nefrologia. 2011;33(1):93-108.

58. K/DOQI clinical practice guidelines for chronic kidney disease: evaluation, classification, and stratification. American journal of kidney diseases 2002 Feb;39(2 Suppl 1):S1-266. PubMed PMID: 11904577.

59. Kidney Disease: Improving Global Outcomes. 2012 KDIGO Clinical Practice Guideline for the Evaluation and Management of Chronic Kidney Disease. Kidney international Supplement. 2013;3:5-14. 
60. Lee C, Almagor O, Dunlop DD, Manzi S, Spies S, Chadha AB, et al. Disease damage and low bone mineral density: an analysis of women with systemic lupus erythematosus ever and never receiving corticosteroids. Rheumatology. 2006 Jan;45(1):53-60. PubMed PMID: 16278288.

61. Bultink IE, Lems WF, Kostense PJ, Dijkmans BA, Voskuyl AE. Prevalence of and risk factors for low bone mineral density and vertebral fractures in patients with systemic lupus erythematosus. Arthritis and rheumatism. 2005 Jul;52(7):2044-50. PubMed PMID: 15986345.

62. Dhillon VB, Davies MC, Hall ML, Round JM, Ell PJ, Jacobs HS, et al. Assessment of the effect of oral corticosteroids on bone mineral density in systemic lupus erythematosus: a preliminary study with dual energy x ray absorptiometry. Annals of the rheumatic diseases. 1990 Aug;49(8):624-6. PubMed PMID: 2396869. Pubmed Central PMCID: 1004178 .

63. Sels F, Dequeker J, Verwilghen J, Mbuyi-Muamba JM. SLE and osteoporosis: dependence and/or independence on glucocorticoids. Lupus. 1996 Apr;5(2):89-92. PubMed PMID: 8743120.

64. Forero V HF, Fonseca EF, Tagle BU, Martinez G, Blanca P. Histomorfometria osea em ninos com Lupus Generalizado - Hospital Infantil de Mexico Federico Gomez. In: XV Congresso SLANH/ VI Congresso Iberoamericano de Nefrologia. Cidade do Mexico; 2009. Abstract 1564373.

65. Takayanagi H. Osteoimmunology: shared mechanisms and crosstalk between the immune and bone systems. Nature reviews Immunology. 2007 Apr;7(4):292-304. PubMed PMID: 17380158.

66. Pacifici R, Rifas L, Teitelbaum S, Slatopolsky E, McCracken R, Bergfeld M, et al. Spontaneous release of interleukin 1 from human blood monocytes reflects bone formation in idiopathic osteoporosis. Proceedings of the National Academy of Sciences of the United States of America. 1987 Jul;84(13):4616-20. PubMed PMID: 3496597. Pubmed Central PMCID: 305141.

67. Mundy GR. Osteoporosis and inflammation. Nutrition reviews. 2007 Dec;65(12 Pt 2):S147-51. PubMed PMID: 18240539.

68. Horton JE, Raisz LG, Simmons HA, Oppenheim JJ, Mergenhagen SE. Bone resorbing activity in supernatant fluid from cultured human peripheral blood leukocytes. Science. 1972 Sep 1;177(4051):793-5. PubMed PMID: 5052733. 
69. Clowes JA, Riggs BL, Khosla S. The role of the immune system in the pathophysiology of osteoporosis. Immunological reviews. 2005 Dec;208:207-27. PubMed PMID: 16313351.

70. McLean RR. Proinflammatory cytokines and osteoporosis. Current osteoporosis reports. 2009 Dec;7(4):134-9. PubMed PMID: 19968917.

71. Weisinger JR, Alonzo E, Bellorin-Font E, Blasini AM, Rodriguez MA, PazMartinez V, et al. Possible role of cytokines on the bone mineral loss in idiopathic hypercalciuria. Kidney international. 1996 Jan;49(1):244-50. PubMed PMID: 8770975.

72. Edwards CJ, Williams E. The role of interleukin-6 in rheumatoid arthritisassociated osteoporosis. Osteoporosis international : a journal established as result of cooperation between the European Foundation for Osteoporosis and the National Osteoporosis Foundation of the USA. 2010 Aug;21(8):1287-93. PubMed PMID: 20229200.

73. Orlic ZC, Turk T, Sincic BM, Stimac D, Cvijanovic O, Maric I, et al. How activity of inflammatory bowel disease influences bone loss. Journal of clinical densitometry : the official journal of the International Society for Clinical Densitometry. 2010 Jan-Mar;13(1):36-42. PubMed PMID: 20171567.

74. Okamoto K, Takayanagi H. Regulation of bone by the adaptive immune system in arthritis. Arthritis research \& therapy. 2011;13(3):219. PubMed PMID: 21635718. Pubmed Central PMCID: 3218874.

75. Ding C, Parameswaran V, Udayan R, Burgess J, Jones G. Circulating levels of inflammatory markers predict change in bone mineral density and resorption in older adults: a longitudinal study. The Journal of clinical endocrinology and metabolism. 2008 May;93(5):1952-8. PubMed PMID: 18285417.

76. Alele JD, Kamen DL. The importance of inflammation and vitamin D status in SLE-associated osteoporosis. Autoimmunity reviews. 2010 Jan;9(3):137-9. PubMed PMID: 19427412.

77. Schoppet M, Preissner KT, Hofbauer LC. RANK ligand and osteoprotegerin: paracrine regulators of bone metabolism and vascular function. Arteriosclerosis, thrombosis, and vascular biology. 2002 Apr 1;22(4):549-53. PubMed PMID: 11950689. 78. Caetano-Lopes J, Canhao H, Fonseca JE. Osteoimmunology--the hidden immune regulation of bone. Autoimmunity reviews. 2009 Jan;8(3):250-5. PubMed PMID: 18722561. 
79. Stolina M, Guo J, Faggioni R, Brown H, Senaldi G. Regulatory effects of osteoprotegerin on cellular and humoral immune responses. Clinical immunology. 2003 Dec;109(3):347-54. PubMed PMID: 14697750.

80. Walsh MC, Kim N, Kadono Y, Rho J, Lee SY, Lorenzo J, et al. Osteoimmunology: interplay between the immune system and bone metabolism. Annual review of immunology. 2006;24:33-63. PubMed PMID: 16551243.

81. Tan EM, Cohen AS, Fries JF, Masi AT, McShane DJ, Rothfield NF, et al. The 1982 revised criteria for the classification of systemic lupus erythematosus. Arthritis and rheumatism. 1982 Nov;25(11):1271-7. PubMed PMID: 7138600.

82. Bombardier C, Gladman DD, Urowitz MB, Caron D, Chang CH. Derivation of the SLEDAI. A disease activity index for lupus patients. The Committee on Prognosis Studies in SLE. Arthritis and rheumatism. 1992 Jun;35(6):630-40. PubMed PMID: 1599520.

83. Weening JJ, D'Agati VD, Schwartz MM, Seshan SV, Alpers CE, Appel GB, et al. The classification of glomerulonephritis in systemic lupus erythematosus revisited. Journal of the American Society of Nephrology : JASN. 2004 Feb;15(2):241-50. PubMed PMID: 14747370.

84. Levey AS, Bosch JP, Lewis JB, Greene T, Rogers N, Roth D. A more accurate method to estimate glomerular filtration rate from serum creatinine: a new prediction equation. Modification of Diet in Renal Disease Study Group. Annals of internal medicine. 1999 Mar 16;130(6):461-70. PubMed PMID: 10075613.

85. Robey PG, Termine JD. Human bone cells in vitro. Calcified tissue international. 1985 Sep;37(5):453-60. PubMed PMID: 2998572.

86. Wergedal JE, Baylink DJ. Characterization of cells isolated and cultured from human bone. Proceedings of the Society for Experimental Biology and Medicine Society for Experimental Biology and Medicine. 1984 May;176(1):60-9. PubMed PMID: 6324225.

87. Dempster DW, Compston JE, Drezner MK, Glorieux FH, Kanis JA, Malluche $\mathrm{H}$, et al. Standardized nomenclature, symbols, and units for bone histomorphometry: a 2012 update of the report of the ASBMR Histomorphometry Nomenclature Committee. Journal of bone and mineral research : the official journal of the American Society for Bone and Mineral Research. 2013 Jan;28(1):2-17. PubMed PMID: 23197339. Pubmed Central PMCID: 3672237. 
88. Gomes SA, dos Reis LM, de Oliveira IB, Noronha IL, Jorgetti V, Heilberg IP. Usefulness of a quick decalcification of bone sections embedded in methyl methacrylate[corrected]: an improved method for immunohistochemistry. Journal of bone and mineral metabolism. 2008;26(1):110-3. PubMed PMID: 18095073.

89. Dos Reis LM, Batalha JR, Munoz DR, Borelli A, Correa PH, Carvalho AB, et al. Brazilian normal static bone histomorphometry: effects of age, sex, and race. Journal of bone and mineral metabolism. 2007;25(6):400-6. PubMed PMID: 17968492.

90. Melsen F, Mosekilde L. Tetracycline double-labeling of iliac trabecular bone in 41 normal adults. Calcified tissue research. 1978 Dec 8;26(2):99-102. PubMed PMID: 737565 .

91. Kidney Disease: Improving Global Outcomes. KDIGO Clinical Practice Guideline for Glomerulonephritis. kidney International Supplements. 2012;2:221-32.

92. Al-Badr W, Martin KJ. Vitamin D and kidney disease. Clinical journal of the American Society of Nephrology : CJASN. 2008 Sep;3(5):1555-60. PubMed PMID: 18450926.

93. Khamiseh G, Vaziri ND, Oveisi F, Ahmadnia MR, Ahmadnia L. Vitamin D absorption, plasma concentration and urinary excretion of 25-hydroxyvitamin D in nephrotic syndrome. Proceedings of the Society for Experimental Biology and Medicine Society for Experimental Biology and Medicine. 1991 Feb;196(2):210-3. PubMed PMID: 1990409.

94. Schmidt-Gayk H, Grawunder C, Tschope W, Schmitt W, Ritz E, Pietsch V, et al. 25-hydroxy-vitamin-D in nephrotic syndrome. Lancet. 1977 Jul 16;2(8029):105-8. PubMed PMID: 69193.

95. Malluche HH, Goldstein DA, Massry SG. Osteomalacia and hyperparathyroid bone disease in patients with nephrotic syndrome. The Journal of clinical investigation. 1979 Mar;63(3):494-500. PubMed PMID: 429568. Pubmed Central PMCID: 371978.

96. Abou-Raya A, Abou-Raya S, Helmii M. The effect of vitamin D supplementation on inflammatory and hemostatic markers and disease activity in patients with systemic lupus erythematosus: a randomized placebo-controlled trial. The Journal of rheumatology. 2013 Mar;40(3):265-72. PubMed PMID: 23204220.

97. Mok CC, Birmingham DJ, Leung HW, Hebert LA, Song H, Rovin BH. Vitamin D levels in Chinese patients with systemic lupus erythematosus: relationship with 
disease activity, vascular risk factors and atherosclerosis. Rheumatology. 2012 Apr;51(4):644-52. PubMed PMID: 21719424.

98. Matsuo K, Irie N. Osteoclast-osteoblast communication. Archives of biochemistry and biophysics. 2008 May 15;473(2):201-9. PubMed PMID: 18406338.

99. Graves DT, Jiang Y, Valente AJ. The expression of monocyte chemoattractant protein-1 and other chemokines by osteoblasts. Frontiers in bioscience : a journal and virtual library. 1999 Jul 1;4:D571-80. PubMed PMID: 10393126.

100. Li X, Qin L, Bergenstock M, Bevelock LM, Novack DV, Partridge NC. Parathyroid hormone stimulates osteoblastic expression of $\mathrm{MCP}-1$ to recruit and increase the fusion of pre/osteoclasts. The Journal of biological chemistry. 2007 Nov 9;282(45):33098-106. PubMed PMID: 17690108.

101. Kim MS, Magno CL, Day CJ, Morrison NA. Induction of chemokines and chemokine receptors CCR2b and CCR4 in authentic human osteoclasts differentiated with RANKL and osteoclast like cells differentiated by MCP-1 and RANTES. Journal of cellular biochemistry. 2006 Feb 15;97(3):512-8. PubMed PMID: 16211583.

102. Koch AE, Kunkel SL, Harlow LA, Johnson B, Evanoff HL, Haines GK, et al. Enhanced production of monocyte chemoattractant protein-1 in rheumatoid arthritis. The Journal of clinical investigation. 1992 Sep;90(3):772-9. PubMed PMID: 1522232. Pubmed Central PMCID: 329929.

103. Lu Y, Cai Z, Xiao G, Keller ET, Mizokami A, Yao Z, et al. Monocyte chemotactic protein-1 mediates prostate cancer-induced bone resorption. Cancer research. 2007 Apr 15;67(8):3646-53. PubMed PMID: 17440076.

104. Wise GE, Frazier-Bowers S, D'Souza RN. Cellular, molecular, and genetic determinants of tooth eruption. Critical reviews in oral biology and medicine : an official publication of the American Association of Oral Biologists. 2002;13(4):323-34. PubMed PMID: 12191959.

105. Aggarwal R, Ghobrial IM, Roodman GD. Chemokines in multiple myeloma. Experimental hematology. 2006 Oct;34(10):1289-95. PubMed PMID: 16982321. Pubmed Central PMCID: 3134145.

106. Chen S, Sims GP, Chen XX, Gu YY, Chen S, Lipsky PE. Modulatory effects of 1,25-dihydroxyvitamin D3 on human B cell differentiation. Journal of immunology. 2007 Aug 1;179(3):1634-47. PubMed PMID: 17641030. 
107. Ben-Zvi I, Aranow C, Mackay M, Stanevsky A, Kamen DL, Marinescu LM, et al. The impact of vitamin D on dendritic cell function in patients with systemic lupus erythematosus. PloS one. 2010;5(2):e9193. PubMed PMID: 20169063. Pubmed Central PMCID: 2821911.

108. Lewiecki EM. Denosumab update. Current opinion in rheumatology. 2009 Jul;21(4):369-73. PubMed PMID: 19424068.

109. Cummings SR, San Martin J, McClung MR, Siris ES, Eastell R, Reid IR, et al. Denosumab for prevention of fractures in postmenopausal women with osteoporosis. The New England journal of medicine. 2009 Aug 20;361(8):756-65. PubMed PMID: 19671655.

110. Papapoulos S, Chapurlat R, Libanati C, Brandi ML, Brown JP, Czerwinski E, et al. Five years of denosumab exposure in women with postmenopausal osteoporosis: results from the first two years of the FREEDOM extension. Journal of bone and mineral research : the official journal of the American Society for Bone and Mineral Research. 2012 Mar;27(3):694-701. PubMed PMID: 22113951. Pubmed Central PMCID: 3415620.

111. Dore RK, Cohen SB, Lane NE, Palmer W, Shergy W, Zhou L, et al. Effects of denosumab on bone mineral density and bone turnover in patients with rheumatoid arthritis receiving concurrent glucocorticoids or bisphosphonates. Annals of the rheumatic diseases. 2010 May;69(5):872-5. PubMed PMID: 19734132.

112. von Moos R, Body JJ, Egerdie B, Stopeck A, Brown JE, Damyanov D, et al. Pain and health-related quality of life in patients with advanced solid tumours and bone metastases: integrated results from three randomized, double-blind studies of denosumab and zoledronic acid. Supportive care in cancer : official journal of the Multinational Association of Supportive Care in Cancer. 2013 Dec;21(12):3497-507. PubMed PMID: 23975226.

113. Casas A, Llombart A, Martin M. Denosumab for the treatment of bone metastases in advanced breast cancer. Breast. 2013 Oct;22(5):585-92. PubMed PMID: 23759273. 